Article

\title{
Design for Disassembly (DfD) and Augmented Reality (AR): Case Study Applied to a Gearbox
}

\author{
Leonardo Frizziero *(D), Alfredo Liverani $\mathbb{D}^{D}$, Gianni Caligiana $\mathbb{D}^{\circ}$, Giampiero Donnici $\mathbb{D}^{\mathbb{D}}$ and \\ Luca Chinaglia
}

Department of Industrial Engineering, Alma Mater Studiorum University of Bologna, Viale Risorgimento, 2, I-40136 Bologna, Italy; alfredo.liverani@unibo.it (A.L.); gianni.caligiana@unibo.it (G.C.); giampiero.donnici@unibo.it (G.D.); luca.chinaglia2@studio.unibo.it (L.C.)

* Correspondence: leonardo.frizziero@unibo.it; Tel.: +39-051-209-3436

Received: 6 March 2019; Accepted: 12 April 2019; Published: 1 May 2019

check for updates

\begin{abstract}
Today's market drives companies to change, adapt, and compete. Many consumers are increasingly looking at price, without sacrificing quality. In order to be attractive to the customer, companies must be able to offer the required quality at the lowest possible price. The life cycle of many products has been shortened compared to the past because now technologies are evolving faster. For these reasons, it is important that companies reevaluate all the operations that are carried out within them, to optimize them and eventually adopt new technologies if they offer interesting opportunities. In this discussion, we first study the design for disassembly, a technique that can bring several advantages during the life cycle of a component, offering the possibility of reducing time and cost of disassembling a product, and better reuse of the different materials of which it is composed. Subsequently, augmented reality is discussed, and how this technology is exploited in the world, especially in the industrial sector. During the work, we discuss a case study, with the gearbox being the object of analysis. This allows us to apply the theoretical concepts illustrated in a concrete way, allowing for a better understanding of the topics.
\end{abstract}

Keywords: gearbox; design for disassembly; augmented reality; computer aided design (CAD)

\section{Introduction}

The present paper aims to introduce a new procedure for improving maintenance processes in industrial engineering and production. Design for disassembly (DfD) is a known, scientifically developed method that only now is gaining new interest goals working together with augmented reality. In fact, if DfD is used for guessing the right way for disassembling a mechanism, augmented reality (AR) could be the right way to visualize the process, transforming it from a theoretical exercise to an industrial real application, mostly useful for writing up a new digital user manual.

DfD finds the best sequence for disassembling the specific assembly, while AR can demonstrate, in a 3D modality, how the abovementioned sequence is embodied in the industrial process, thereby helping workers during maintenance processes.

The DfD falls within the broader category of the design for the environment (DfE), which aims to optimize the control of a product, a process, or a service in order to improve its compatibility with the environment [1-3]. It is therefore able to reduce the environmental impact, taking into consideration life cycle-related problems such as, for example, extracting raw materials and their processing, product realization, transport, use, disposal, and recycling of the product itself, as well as the individual parts of which it is composed [4,5].

Recycling and reuse are noble intentions, but if a product cannot be disassembled with precision and effectiveness, such operations are not possible, or they become prohibitive in terms of cost. From 
this, it follows that a correct design and a continuous improvement of the disassembly phase are essential to obtain the maximum result in terms of fatigue, cost, and time, using only the essential resources [6,7]. In the literature, often, many applications of DfD are easily found. Moreover, many involve the simple application of AR in many different objects. It could, therefore, be interesting to develop matching combination of these two techniques, giving them a common goal: To improve the maintenance process in industrial engineering and production.

In order to find a new methodology, following these targets, the paper is structured as follows: First, there is an introduction to the DfD methodology; then, some existing disassembly sequences methods are listed; after this analysis, a new disassembly sequence method is proposed; all the disassembly methodologies is compared following the times criterion; the best sequence is chosen and implemented in CAD; finally, the same best sequence is implemented in the AR environment. AR gives added value to $\mathrm{CAD}$, because in an industrial world, it would be rapidly understood by workers during their job practices.

\section{Materials and Methods (DfD and AR)}

\subsection{Design for Disassembly (DfD)}

The disassembly of an object or a machine consists of the systematic disassembly of the various parts that compose it. The design for disassembly, more commonly known as DfD, is a design approach that allows easier recovery of parts, components, and materials that make up the product at the end of its life. DfD is therefore a design method that aims to improve quality and reduce time and costs related to disassembly of a product, considering waste and environment. Although DfD methods have existed for years, it is only in the last period that they have been applied more efficiently and consciously. This is due to the fact that over time, the market has accelerated its pace, proposing new goods in ever-shorter times and increasingly competitive prices (an example is the technological obsolescence of smartphones), in addition to the presence of directing pressures to the DfE, such as WEEE (waste electrical and electronic equipment), ELV (end of life vehicles) or RoHS (restriction of hazardous substances).

Disassembly plays an important role, as it can be performed for different purposes, such as performing preventive maintenance (replacement of a component that has not yet failed) rather than corrective maintenance (replacement or repair of a faulty component) or recycling the material of components that are no longer usable [8].

An essential aspect of DfD is calculating disassembly depth, i.e., the total number of sequential dismantling steps. In fact, it has been determined that the cost of dismantling is almost linear with the depth, while the revenue has a rapid initial increase and then settles down, without further growth as the depth increases. Using more time, energy, and resources in disassembling involves obtaining purer material, thus recovering part of the cost in terms of recycling and recovery. It is therefore a question of optimizing the area where there is more revenue for reasonable costs. For this reason, it is recommended in the DfD to place the most important components in easily accessible areas where possible (Figure 1) [9].

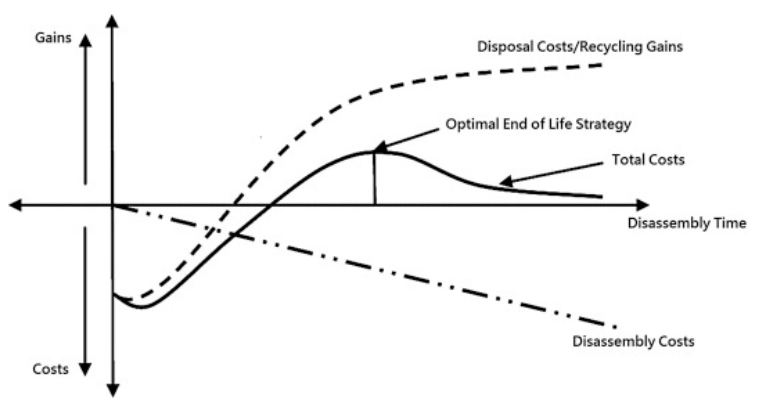

Figure 1. Cost-benefit curve-disassembly depth. 
Among the advantages of the $\mathrm{DfD}$, we therefore see a reduction in production costs, greater technical efficiency, greater flexibility during product development, and a reduction in resources.

\subsubsection{Disassembly Sequence Planning (DSP)}

Disassembly sequence planning, usually indicated with DSP, consists of the realization of a disassembly sequence coherent with the benefits that the DfD offers. The method is based on an efficient representation of the product and on the search for an effective sequence.

First of all, a disassembly can be of several types: We talk about complete disassembly when all the components are disassembled, while we have a selective disassembly when the product is not completely disassembled, but only until one or more specific components, called target components, are reached. Furthermore, we can have a nondestructive disassembly when the removal of the various parts does not entail rupture, thus allowing its revitalization and reuse. This disassembly, if it can be carried out, is generally preferable to destructive disassembling, which instead leads to the breaking of the components during disassembly. The DSP considers the product structure, the direction of removal of the components, the operational constraints, the complexity in representing the product, and the planning of the sequence. For this reason, there are guidelines that allow a sequence to be realized effectively and efficiently. First of all, the selection and use of materials and fasteners (connecting and/or fixing elements), component design, and product architecture must be considered.

To obtain a significant sequence, it is important to choose compatible recyclable materials, avoid using materials that require separation before disassembling, use components of the same type, and minimize and standardize the fasteners (for example using the same type of screw), thus making the components more easily separable and avoiding permanent fixings and toxic or dangerous materials. It is also important to remove the most relevant materials and components, to speed up operations by choosing between destructive and nondestructive methods, to move the product to be processed as little as possible, and to use electric or pneumatic tools, paying attention to the fatigue and effort of any person must support, as in the medium to long term, they can negatively affect their health and performance.

Below, we present two algorithms of DSP where it is useful to apply the DfD [10].

2.1.2. 1st Method: "Research on the Selectable Disassembly Strategy of Mechanical Parts Based on the Generalized CAD Model"

This first method, introduced by Jianjun Yi, Bin Yu, Lei Du, Chenggang Li, and Diqing Hu, defines the order in which the components are removed to disassemble a selected component, called $C_{x}$. Once the $C_{x}$ component has been defined, it is possible to identify all the possible sequences that allow the removal of our target component and, once identified, choose the sequence that best meets the objective function (for example, you can opt for the sequence with the minor number of operations to be performed, rather than the one that requires the least amount of time to be performed).

It is possible to define a generic $C_{i}$ component in two different ways depending on the case series. A component $C_{i}$ is defined as $d$-dependent when it is in contact with several elements that must be removed to allow disassembly of $C_{i}$, while 1-dependent is indicated as the case where it can be removed after removing only one component with which it is in contact.

The identification of the various disassembling sequences was carried out through the use of the disassembly wave: We imagined that the $C_{x}$ component is the origin of a wave that, starting at the time $\tau_{1}$, propagates in space, striking the elements in contact with the target component. Subsequently, a second wave, emitted at the instant $\tau_{2}$, touches the elements adjacent to the parts previously involved. This proceeds in an iterative way until all the elements have been involved, and we indicate with $\tau_{\mathrm{n}}$ the generic instant in which the last wave is emitted. To then obtain the disassembly sequence (s), we began by removing the components present in the outermost disassembly wave (hence, the one corresponding to $\tau_{n}$ ) and, proceeding backwards, we gradually removed the present components 
of the innermost wave disassembly, achievement of the $C_{x}$ target component (the only component belonging to the instant $\tau_{0}$ ).

The whole is graphically represented by the removal influence graph (RG) (Figure 2), in which the generic components $C_{i}$ are represented with nodes, while it is indicated with the aid of arrows that the 1-dependent and d-dependent relationships connect the nodes, thus allowing to understand the dependencies between the components and providing a representation of the possible disassembly sequence (s). The disassembly wave instead is represented with a curve that connects all the nodes (i.e., the components) that are involved at the same instant $\tau_{i}$ generic.

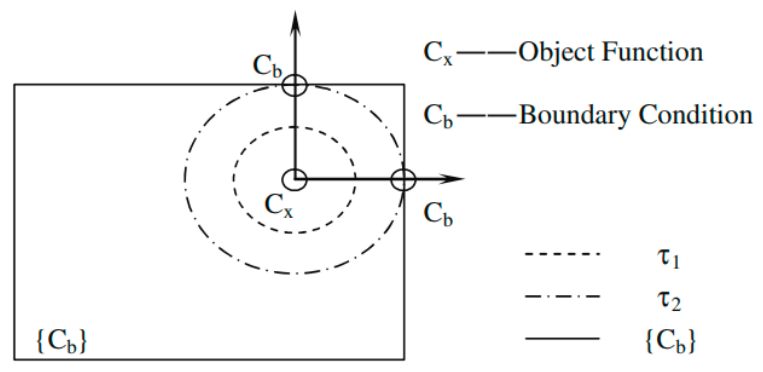

Figure 2. Removal influence graph (RG).

In order to better understand these concepts, a simple example illustrated by the authors of the method is shown. Consider the $\mathrm{C}_{6}$ component as a target component of Figure 3a (for simplicity, it is considered a two-dimensional case, but similar reasoning can be done even in the three-dimensional case) [11].

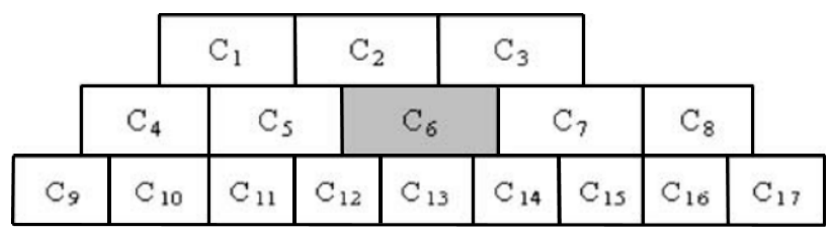

(a)

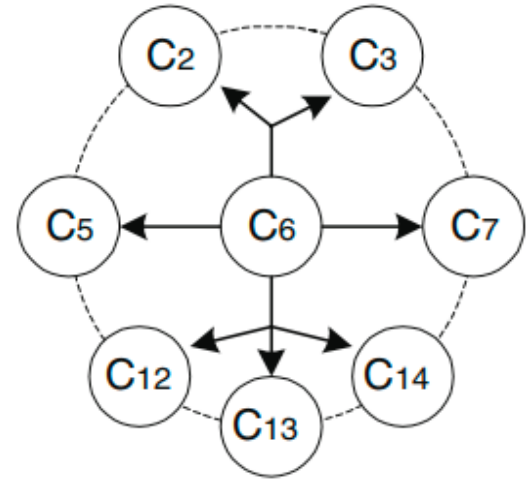

(b)

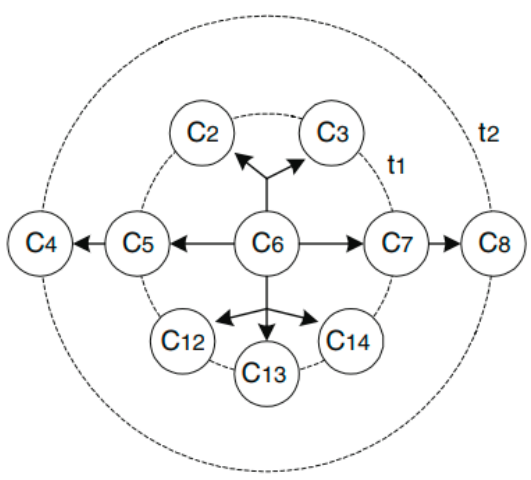

(c)

Figure 3. (a) Example application 1st method; (b,c) example of 1st method: Disassembly wave.

In this case, the $\mathrm{C}_{6}$ component has four possible ways in which it can be removed: Up, down, right or left. The first disassembly wave at the instant $t_{1}$ hits the components $C_{2}$ and $C_{3}$ at the top, $\mathrm{C}_{7}$ at the right, $\mathrm{C}_{14}, \mathrm{C}_{13}$, and $\mathrm{C}_{12}$ at the bottom, and $\mathrm{C}_{5}$ at the left. $\mathrm{C}_{6}$ can be considered 1-dependent with respect to $\mathrm{C}_{5}$ or $\mathrm{C}_{7}$, whereas it is considered d-dependent with respect to the other components. To remove the $C_{5}$ and $C_{7}$ components, it is necessary to also remove $C_{4}$ and $C_{8}$ (components that are involved by a second disassembly wave at the instant $t_{2}$ ) (Figure $3 b, c$ ). 
Thus, four possible disassembly sequences are obtained:

$\mathrm{S}_{1}=\mathrm{C}_{2}, \mathrm{C}_{3}$

$\mathrm{S}_{2}=\mathrm{C}_{8}, \mathrm{C}_{7}$

$\mathrm{S}_{3}=\mathrm{C}_{12}, \mathrm{C}_{13}, \mathrm{C}_{14}$

$\mathrm{S}_{4}=\mathrm{C}_{4}, \mathrm{C}_{5}$

\subsubsection{2nd Method: "Partial-Parallel Disassembly Sequence Planning for Complex Products"}

This method, presented by Fei Tao, Luning Bi, Ying Zuo and A.Y.C. Nee, allows the planning of partial and/or parallel disassembly sequences using a DPM (disassembly precedence matrix), i.e., a matrix of disassembly precedences designed to improve the efficiency of the sequence with which the various parts are removed. This method considers a nondestructive disassembly of components and fasteners [12].

The DPM is made up of four submatrices: The CFM, the FCM, the CCM, and the FFM. The first thing to do, therefore, is the drafting of these submatrices.

In the CFM (components fasteners matrix), the vector of the $j$-th row represents the limitations due to the presence of the fasteners that the component $j$ has along the directions in which it can be removed (if we are in a two-dimensional space, the possible directions are $-x,+x,-y$, and $+y$, while in a three-dimensional space, we also have $-z$ and $+z$ ). If a fastener prevents the movement along the removal direction of the $j$ component, 1 will be inserted in the corresponding cell, otherwise 0 . Therefore, if 1 is present in a certain cell, it means that the component is blocked by the fastener, whereas if 0 is present, the component is not blocked by the fastener along the direction in which it is removed.

In the FCM (fasteners components matrix), the vector of the $i$-th row represents the limitations to which fastener $i$ is subjected due to the presence of one or more components along the possible directions of removal of the fastener. If 1 is present in a cell, the fastener is blocked by the component, whereas if 0 is present instead, the fastener is not blocked by the component along the direction in which it is removed.

In the CCM (components components matrix), the vector of the $j$-th row represents the limitations to which the component $j$ is subjected due to the presence of other components along the possible directions of removal of the component $j$. Thus, if there is 1 in a cell, the $j$ component is blocked by another component, whereas if 0 is present instead, the $j$ component is not blocked by another component along the direction in which it is removed.

The FFM (fasteners fasteners matrix) represents the precedence of disassembling between two fasteners: If 1 is present in a cell, movement of fastener $i$ is prevented by another fastener, while if there is 0 , the fastener $i$ is not blocked by another fastener along the direction in which it is removed.

Unlike static DPM that does not change during the disassembly process, the DPM proposed by the authors is dynamic. In fact, it is modified every time a component or fastener is removed. When an element is removed, the corresponding row and the corresponding column are deleted, thus passing from a matrix that contains $(m \times n)$ elements to one that contains $((m-1) \times(n-1))$, indicating with $m$ the number of rows and with $\mathrm{n}$ the number of columns. Furthermore, in disassembling any modules, considered as subassemblies, the DPM is divided into two or more sub-DPMs, each representing a new branch for disassembling. This dynamic system helps to reduce the size of the DPM and reduces the difficulty in finding feasible solutions.

To know when to remove a fastener or a component, two simple rules are used.

Rule 1 (disassembly of a fastener): The $i$-th fastener (indicated with $\mathrm{F}_{i}$ ) can be removed when FCM $(i,:)=0$ and FFM $(i,:)=0$, where FCM $(i,:)=0$ means that there are no components that block $\mathrm{F}_{i}$ along the disassembly direction, whereas when FFM $(i,:)=0$, there are no other fasteners that have priority over $\mathrm{F}_{i}$. 
Rule 2 (disassembling a component): The $j$-th component (indicated with $C_{j}$ ) can be removed when $\operatorname{CFM}(j,:)=0$ and $\operatorname{CCM}(j,:)=0$, where $\operatorname{CFM}(j,:)=0$ means that all fasteners used to fix $\mathrm{C}_{j}$ have already been removed, whereas when $\mathrm{CCM}(j,:)=0$, there are no more components blocking $\mathrm{C}_{j}$ along the disassembling direction.

To these two rules we can add a third rule in the case where we have to disassemble a module, where by module we mean a set of components and/or fasteners connected to each other. If the product is separated into modules during the disassembly process, it is then possible to disassemble the modules in parallel, thus reducing the overall execution time.

Rule 3 (disassembly of a module): In a module, the previous relationships between the parties become internal limitations. If there are no other 1 in the corresponding DPM lines except for internal limitations, the module can be removed and disassembled into the individual parts.

To generate a partial/parallel disassembly sequence, you need to follow five steps.

Step 1: Randomly generate a disassembly sequence of the fasteners. The random generation system ensures that all possible solutions/combinations are found.

Step 2: Disassemble the fasteners one at a time in the sequence order generated in Step 1. If the current fastener meets Rule 1, remove the fastener and go to Step 3, otherwise go to the next fastener.

Step 3: Remove all components that meet Rule 2.

Step 4: If the disassembly comes to an end (the achievement of the target component in the case of a partial disassembly), the final sequence is obtained. If not, go to Step 5.

Step 5: Check if there are any modules that satisfy Rule 3. If they exist, disassemble them in parallel, otherwise return to Step 2.

The main advantage of this method is to offer the possibility of obtaining different disassembly sequences which, if properly implemented, can offer an optimal solution with respect to a specific objective function. In fact, once a disassembly sequence is obtained starting from a certain order with which to try to remove the components, just modify this order to obtain a final sequence that is probably different from the previous one. If we go to iterate all possible initial combinations (i.e., all the different ways in which to try to remove the fasteners), we will get all the possible disassembling sequences for a given product (obviously according to the rules above) (Figure 4).



Figure 4. Flow chart for the generation of a partial/parallel disassembly sequence.

On the other hand, however, obtaining these results in the case of a complex product is long and demanding, which is why it would be necessary to use a computer that is able to perform the operations automatically.

To better understand the concepts introduced above, an example illustrated by the authors of the method is presented. For simplicity, a two-dimensional case is taken into consideration, but similar reasoning can also be made in the three-dimensional case. Starting from the product illustrated in Figure 5a, the matrices CFM, FCM, CCM, and FFM are made. 




(a)

$\mathrm{CFM}=\left[\begin{array}{cccccc} & F 1 & F 2 & F 3 & F 4 & F 5 \\ C 1 & 1(-\mathrm{x}) & 1(+y) & 1(+x) & 0 & 0 \\ C 2 & 1(-\mathrm{x}) & 0 & 1(+x) & 1(-\mathrm{x}) & 1(+y) \\ C 3 & 0 & 1(+y) & 0 & 0 & 0 \\ C 4 & 0 & 0 & 0 & 1(+x) & 0 \\ C 5 & 0 & 0 & 0 & 0 & 1(+y)\end{array}\right]$

(b)

$$
C C M=\left[\begin{array}{cccccc} 
& C 1 & C 2 & C 3 & C 4 & C 5 \\
C 1 & 0 & 0 & 0 & 0 & 0 \\
C 2 & 0 & 0 & 0 & 0 & 0 \\
C 3 & 0 & 0 & 0 & 0 & 0 \\
C 4 & 1(-\mathrm{x}) & 0 & 0 & 0 & 1(-\mathrm{x}) \\
C 5 & 1(+\mathrm{y}) & 0 & 1(+\mathrm{y}) & 0 & 0
\end{array}\right]
$$

(d)

$$
\mathrm{FCM}=\left[\begin{array}{cccccc} 
& C 1 & C 2 & C 3 & C 4 & C 5 \\
F 1 & 0 & 0 & 0 & 0 & 0 \\
F 2 & 0 & 0 & 0 & 0 & 0 \\
F 3 & 0 & 0 & 0 & 0 & 0 \\
F 4 & 1(-\mathrm{x}) & 0 & 0 & 0 & 0 \\
F 5 & 1(+y) & 0 & 1(+\mathrm{y}) & 0 & 0
\end{array}\right]
$$

(c)

(e)

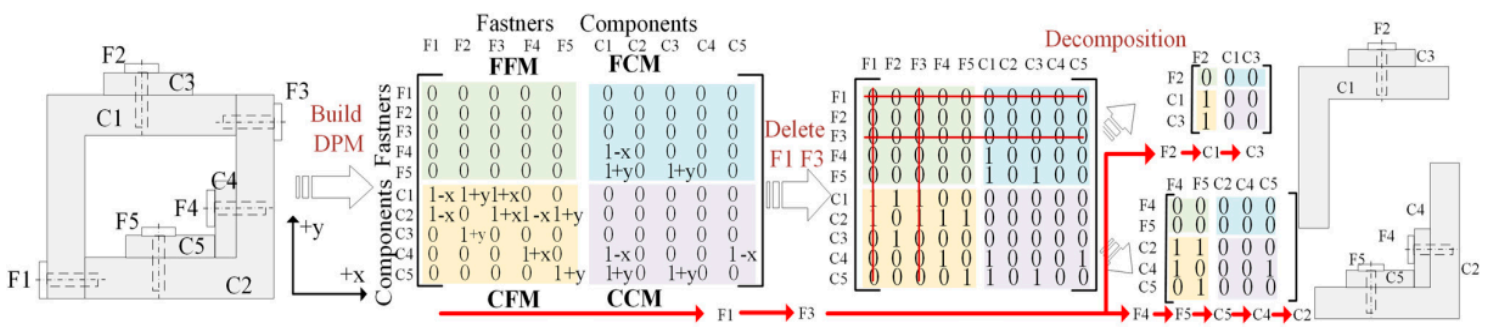

(f)

Figure 5. (a) Example application 2nd method; (b) example of 2nd method: CFM creation; (c) example of 2nd method: FCM creation. (d) Example of 2nd method: CCM creation; (e) example of 2nd method: creation of FFM; (f) application example 2nd method: DPM creation and obtaining disassembly sequences.

In CFM, for example, it can be seen that $C_{1}$ is blocked by $F_{1}$ in the $-x$ direction, while in FCM, it is noted that $F_{5}$ is blocked by $C_{1}$ in the +y direction. Moreover, in the CCM, we can see that $C_{3}$ is in the direction of removal $+\mathrm{y}$ of $\mathrm{C}_{5}$, while from the CCM, we deduce that there are no constraints between the fasteners because there are only 0 .

At this point, the DPM can be created by "joining" the four matrices previously obtained. It is therefore decided to try to remove the fasteners in the following order: $F_{1}, F_{3}, F_{2}, F_{4}$, and $F_{5}$.

The first fastener to be removed is just $F_{1}$ because it satisfies Rule 1: This involves deleting from the row and the column of $F_{1}$. Since it is not possible to disassemble any of the components, $F_{3}$ is removed, eliminating the respective row and column. At this point, there is the possibility of separating the product into two modules: $\left(\mathrm{F}_{2}, \mathrm{C}_{1}, \mathrm{C}_{3}\right)$ and $\left(\mathrm{F}_{4}, \mathrm{~F}_{5}, \mathrm{C}_{2}, \mathrm{C}_{4}, \mathrm{C}_{5}\right)$. These modules will be disassembled separately. If, however, as an initial sequence with which to try to remove the fasteners, we decided to use $F_{1}, F_{2}, F_{3}, F_{4}, F_{5}$, it would not have been possible to divide the product into modules, and we would have obtained a different final sequence. 


\subsubsection{Application of Design for Disassembly to the Case Study of a Speed Gearbox}

A case study is now illustrated in order to better understand and apply all the concepts presented up to now. To this goal, we decided to represent a speed gearbox through a 3D modeling program, thus orienting ourselves towards the metalworking sector. Then we applied the above methods to the gearbox mentioned, obtaining two different disassembly sequences. To these two sequences, we added a third one that we invented after choosing some logical criteria with which to obtain it. To better understand the advantages that design for disassembly offers, we finally made a comparison between the three sequences, evaluating them first according to the temporal criterion and, subsequently, by performing an economic analysis [13].

\subsubsection{D CAD Modeling}

For the 3D representation of the gearbox, it was decided to use a 3D CAD Modeler, i.e., Solidworks (version 2016), which is a CAD software (computer aided design) developed by Dassault Systèmes, used to draw and for three-dimensional design parametrics. We selected Solidworks because it is a program created specifically for mechanical engineering, and its use is quite intuitive. Moreover, it is possible to find various sources of information on the Internet (for example, forums and video tutorials) that allow easily acquiring greater knowledge about the software.

The gearbox represented is the RV 250 screw gearbox of the Rossi Motoriduttori Soc. of Modena (Figure 6). Starting from the assembly (represented in 2D), we obtained the bill of materials (BOM), and then we made every single component in $3 \mathrm{D}$, finally obtaining the gearbox in question by assembling the various components and inserting the properties and the relative constraints between them.

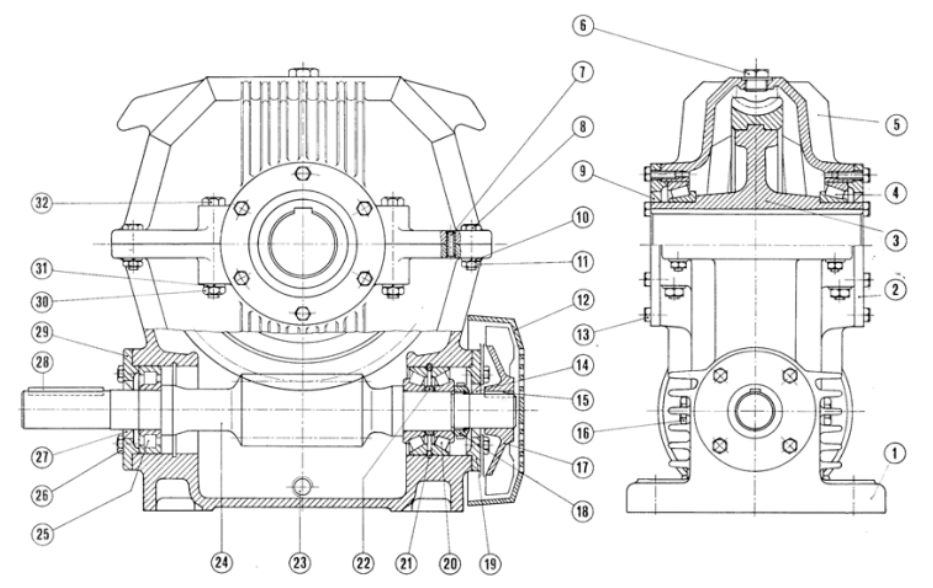

Figure 6. RV 250 gearbox from the design of the Rossi Motoriduttori-Modena.

About the bearings, in the bill of materials, we have written in brackets the name of the models produced by SKF (a leader company in bearings production): Subsequently, we downloaded the relative models from the company's website and used them for study's purposes (Table 1).

It is important to pay attention to the transmission shaft with endless gear and to the helical toothed wheel, as they are the two most important components because they are responsible for the motion. The screw gearboxes, in fact, are able to connect shafts with skewed axes (i.e., not belonging to the same plane and, therefore, not parallel to each other): Generally, the toothed wheel is the conducted element and engages on an endless screw, which acts as a driving force.

In order to realize the profile of the endless screw, the "extrusion with sweep" function was used, supplying the profile of an involute tooth as a profile and a helix path, while to make the teeth of the toothed wheel, the "cut with sweep" function was adopted, using as the profile that of an evolving tooth and as the path a segment of the required length and inclination (Figures 7 and 8). 
Table 1. Bill of materials (BOM).

\begin{tabular}{|c|c|c|}
\hline Particular Number & Description & Quantity \\
\hline 1 & Lower casing & 1 \\
\hline 2 & Flange 6 holes & 2 \\
\hline 3 & Screw wheel & 1 \\
\hline 4 & $\begin{array}{c}\text { Bearing } 120 \text { KB } 20 \text { UNI } 6042 \\
(32024 \text { X) }\end{array}$ & 2 \\
\hline 5 & Upper casing & 1 \\
\hline 6 & Load cap G $\frac{3}{4}$ & 1 \\
\hline 7 & Elastic plug $10 \times 40$ ISO 8752 & 2 \\
\hline 8 & Screw M14 × 65 ISO $4014-8.8$ & 4 \\
\hline 9 & Oil seal ø120 & 2 \\
\hline 10 & Rosetta B 14 UNI 1751 & 4 \\
\hline 11 & Nut M14 ISO 4032 & 4 \\
\hline 12 & Fan cover & 1 \\
\hline 13 & Screw M12 × 40 ISO $4017-8.8$ & 12 \\
\hline 14 & Oil seal ø54 & 1 \\
\hline 15 & Tab B $12 \times 10 \times 50$ UNI 6604 & 1 \\
\hline 16 & Drain plug $G \frac{3}{4}$ & 4 \\
\hline 17 & Fan & 1 \\
\hline 18 & Ring nut M60 × 2 DIN 981 & 1 \\
\hline 19 & 4-hole flange part fan & 1 \\
\hline 20 & Bearing 60 KB 23 UNI 4222 (31312) & 2 \\
\hline 21 & Elastic ring 130 UNI 7437 & 1 \\
\hline 22 & Spacer $\varnothing 60$ & 1 \\
\hline 23 & Exhaust hole $G \frac{3}{4}$ & 4 \\
\hline 24 & $\begin{array}{c}\text { Transmission shaft with endless } \\
\text { screw }\end{array}$ & 1 \\
\hline 25 & $\begin{array}{c}\text { Bearing } 60 \text { RF } 3 \text { UNI } 4214 \text { (NJ } 312 \\
\text { ECPH) }\end{array}$ & 1 \\
\hline 26 & Screw M10 × 30 ISO $4017-8.8$ & 8 \\
\hline 27 & Oil seal ø60 & 1 \\
\hline 28 & Tongue A $16 \times 12 \times 90$ UNI 6604 & 1 \\
\hline 29 & Flange 4 bearing sealing holes & 1 \\
\hline 30 & Nut M20 ISO 4032 & 4 \\
\hline 31 & Rosette B 20 UNI 1751 & 4 \\
\hline 32 & Screw M20 × 150 ISO $4014-8.8$ & 4 \\
\hline
\end{tabular}

Figure 7. Transmission shaft with endless.

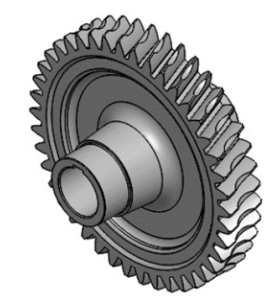

Figure 8. Screw wheel.

The constructive data of the screw and the wheel are shown below (Table 2), as well as a representation of their assembly. 
Table 2. Constructive data.

\begin{tabular}{|c|c|c|c|}
\hline \multirow{2}{*}{ Terms } & & \multicolumn{2}{|c|}{ Construction Data } \\
\hline & & Screw & Screw Wheel \\
\hline Number of Teeth & $\mathbf{z}$ & $z_{1}=1$ & $\mathrm{z}_{2}=42$ \\
\hline Normal modulus (mm) & $m_{n}$ & \multicolumn{2}{|c|}{$m_{n}=9.9226$} \\
\hline Axial modulus (mm) & $m_{x}$ & \multicolumn{2}{|c|}{$\mathrm{m}_{\mathrm{x}}=10$} \\
\hline Average diameter (mm) & $\mathrm{d}_{\mathrm{m}}$ & $\mathrm{d}_{\mathrm{m} 1}=80$ & $\mathrm{~d}_{\mathrm{m} 2}=420$ \\
\hline Diameter of head (mm) & $\mathrm{d}_{\mathrm{a}}$ & $\mathrm{d}_{\mathrm{a} 1}=99.84$ & $\mathrm{~d}_{\mathrm{a} 2}=439.84$ \\
\hline Pressure angle & $\alpha$ & \multicolumn{2}{|c|}{$\alpha=20^{\circ}$} \\
\hline Normal path (mm) & $\mathrm{p}_{\mathrm{n}}$ & \multicolumn{2}{|c|}{$\mathrm{p}_{\mathrm{n}}=31.157$} \\
\hline Axial path (mm) & $\mathrm{p}_{\mathrm{a}}$ & \multicolumn{2}{|c|}{$p_{a}=31.416$} \\
\hline Helix angle & $\beta$ & \multicolumn{2}{|c|}{$\beta=7^{\circ} 8^{\prime}$} \\
\hline Wheelbase (mm) & a & \multicolumn{2}{|c|}{$a=250$} \\
\hline Teeth & & \multicolumn{2}{|c|}{ right } \\
\hline
\end{tabular}

Using the data provided, we obtained other useful information to represent the components:

$\begin{array}{ll}\text { Addendum } & \mathrm{h}_{\mathrm{a}}=\mathrm{m}_{\mathrm{n}} \\ \text { Dedendum } & \mathrm{h}_{\mathrm{f}}=1,25 \mathrm{~m}_{\mathrm{n}} \\ \text { Tooth height } & \mathrm{h}=\mathrm{h}_{\mathrm{a}}+\mathrm{h}_{\mathrm{f}} \\ \text { Diameter of the foot } & \mathrm{d}_{\mathrm{f}}=\mathrm{d}_{\mathrm{m}}-2 \mathrm{~h}_{\mathrm{f}}\end{array}$

In the following figures (Figures 9 and 10), some images of details of the assembly (in Figure 11a, it is also possible to notice the software interface) and of the exploded view (Figure 12) are shown instead.

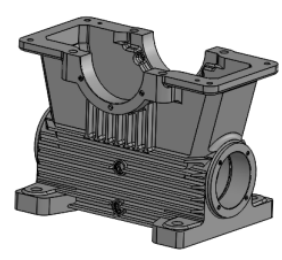

Figure 9. Lower casing.

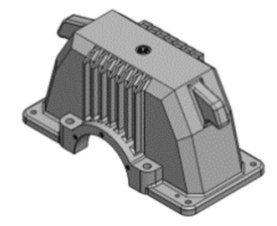

Figure 10. Upper casing.

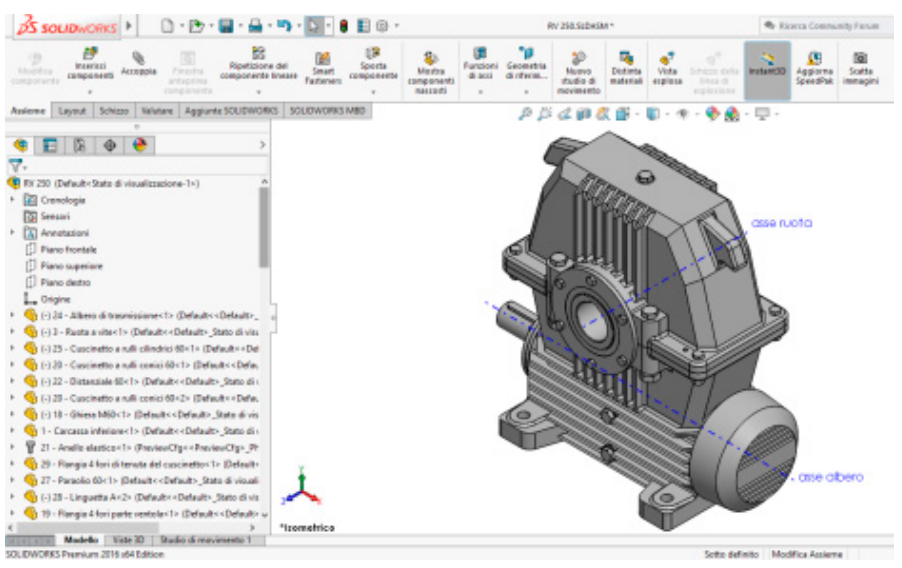

(a)



(b)

Figure 11. (a) Gearbox assembly;(b) axonometry of gearbox assembly. 


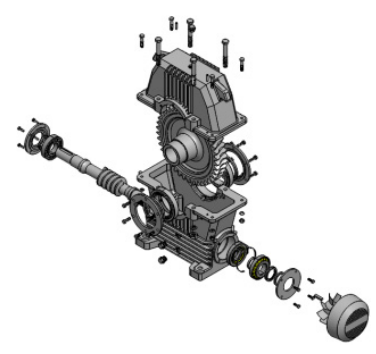

Figure 12. Exploded view.

\subsubsection{Application of the First Method}

In this paragraph, the first method presented about the design for disassembly is applied to the case study. We wanted to perform a disassembly that allowed us to remove the drive shaft with an endless screw, which was considered our target component. The choice of the screw as a target component is reasonable because it is one of the components most subjected to stress and wear. For this reason, it is more likely that it will fail or in any case be replaced to perform preventive maintenance. In order to remove the shaft, the lower casing was not taken into consideration as it provides the support base to our gearbox, and the screw is contained inside.

Let us consider, as a first step, the oil drain at the lowest level, thus allowing us to disassemble safely. Then, remove the lower drain plugs, one on the left and one on the right. It is not necessary to remove the two upper drain plugs, which is why they were not considered and were not separated from the lower casing.

From Figure 13a,b, it is possible to observe the expansion of the disassembly wave in the various instants $\tau$.



(a)



(b)

Figure 13. $(\mathbf{a}, \mathbf{b})$ Disassembly wave applied to the gearbox.

The disassembling sequence obtained is as follows: 16 SX INF, 16 DX INF, 12, 17, 15, 26 DX, 11, 30, 31, 10, 19, 14, 18, 28, 8, 32, 6, 7, 13 SX, 13 DX, 2 DX, 2 SX, 9 SX, 9 DX, 5, 20 DX, 26 SX, 29, 27, 4 SX, 4 DX, 22, 21, 3, 20 SX, 25, 24.

In the disassembly sequence, the numbers are representative of the components and fasteners according to the numbering shown in the bill of materials (Table 1). Moreover, for the sake of simplicity of reading, it was implied that when an element which is present several times is removed in the gearbox, in reality, that element is removed as many times as those it is present: For example, when an M20 nut (number 30) is unscrewed, in reality, we proceeded by unscrewing all four M20 nuts present. 
Finally, for those components or fasteners indicated together with the wording DX (right) or SX (left), the reference is given with respect to the overall starting drawing (Figure 6).

Observing the result obtained, it can be noticed how this method leads to a complete disassembly of the gearbox.

\subsubsection{Application of the Second Method}

To apply the second method of design for disassembly to the case study, we started with the construction of the four submatrices, as well as the DPM. The general considerations made for the first method (target component, removal of the lower caps, numbers indicating the elements, etc.) also apply to this second method. First of all, however, a subdivision between components and fasteners is necessary, and the direction of removal of each element must be identified. In Table 3, it is possible to observe how the components and fasteners have been grouped and renamed, in addition to the relative removal verses.

Table 3. (a) Components partition. (b) Fasteners partition.

\begin{tabular}{ccc}
\hline \multicolumn{3}{c}{ (a) } \\
\hline Nr. Component & $\mathbf{N}^{\circ}$ BOM & Direction of Removal \\
\hline C1 & 1 & $/$ \\
C2 SX & 2 & 000010 \\
C2 DX & 2 & 000001 \\
C3 & 3 & 000100 \\
C4 SX & 4 & 000010 \\
C4 DX & 4 & 000001 \\
C5 & 5 & 000100 \\
C6 & 6 & 000100 \\
C7 SX & 9 & 000010 \\
C7 DX & 9 & 000001 \\
C8 & 12 & 010000 \\
C9 & 14 & 010000 \\
C10 & 17 & 010000 \\
C11 & 19 & 010000 \\
C12 SX & 20 & 010000 \\
C12 DX & 20 & 010000 \\
C13 & 22 & 010000 \\
C14 & 24 & 110000 \\
C15 & 25 & 100000 \\
C16 & 27 & 100000 \\
C17 & 29 & 100000 \\
\hline
\end{tabular}

\begin{tabular}{ccc}
\hline \multicolumn{3}{c}{ Fasteners } \\
\hline Nr. Fasteners & $\mathbf{N}^{\circ}$ BOM & Direction of Removal \\
\hline F1 & 7 & 001100 \\
F2 & 8 & 000100 \\
F3 & 10 & 001000 \\
F4 & 11 & 001000 \\
F5 SX & 13 & 000010 \\
F5 DX & 13 & 000001 \\
F6 & 15 & 000100 \\
F7 & 18 & 010000 \\
F8 & 21 & 010000 \\
F9 SX & 26 & 100000 \\
F9 DX & 26 & 010000 \\
F10 & 28 & 000100 \\
F11 & 30 & 001000 \\
F12 & 31 & 001000 \\
F13 & 32 & 000100 \\
\hline
\end{tabular}


The removal directions are indicated numerically, represented with 1 if it is possible to remove an element along that determined direction, or with 0 if it is not possible. The order in which the directions are shown is as follows: $-x,+x,-y,+y,-z,+z$. If, for example, we want to represent the possibility of removing a component along the $+x$ direction, we would write 010000 (Table 4).

Table 4. Disassembly directions.

\begin{tabular}{cc}
\hline \multicolumn{2}{c}{ Directions } \\
\hline Cartesian & Numeric \\
\hline$-\mathrm{x}$ & 100000 \\
$+\mathrm{x}$ & 010000 \\
$-\mathrm{y}$ & 001000 \\
$+\mathrm{y}$ & 000100 \\
$-\mathrm{z}$ & 000010 \\
$+\mathrm{z}$ & 000001 \\
\hline
\end{tabular}

It was decided to orient the axes in the way shown in Figure 14.

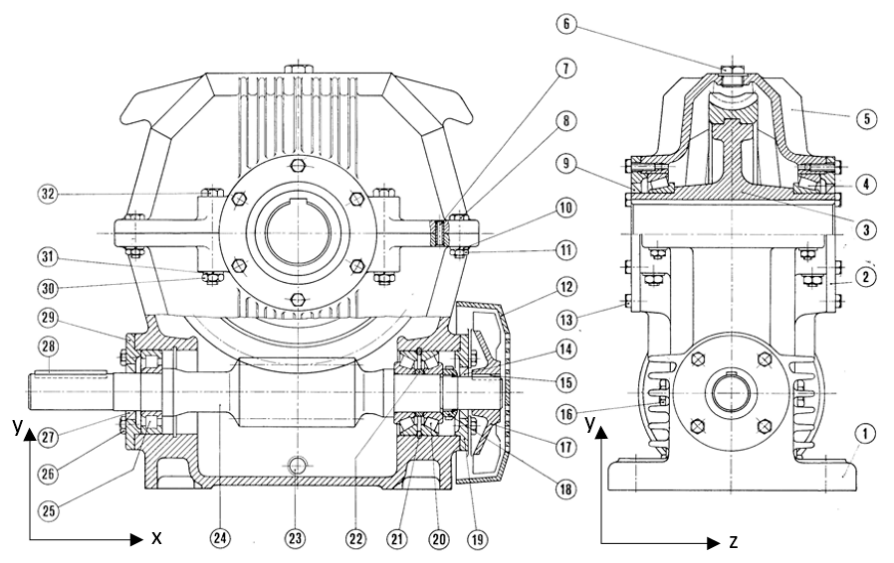

Figure 14. RV 250 gearbox with reference system.

Now let us build the submatrices: CFM (Figure 15), FCM (Figure 16), CCM (Figure 17), and FFM (Figure 18).

\begin{tabular}{|c|c|c|c|c|c|c|c|c|c|c|c|c|c|c|c|}
\hline & F1 & F2 & F3 & F4 & F5 SX & F5 DX & F6 & F7 & F8 & F9 SX & F9 DX & F10 & F11 & F12 & F13 \\
\hline C1 & 110011 & 000100 & 001000 & 001000 & 000010 & 000001 & 0 & 0 & 0 & 100000 & 010000 & 0 & 001000 & 001000 & 000100 \\
\hline C2 SX & 0 & 0 & 0 & 0 & 000010 & 0 & 0 & 0 & 0 & 0 & 0 & 0 & 0 & 0 & 0 \\
\hline C2 DX & 0 & 0 & 0 & 0 & 0 & 000001 & 0 & 0 & 0 & 0 & 0 & 0 & 0 & 0 & 0 \\
\hline C3 & 0 & 0 & 0 & 0 & 0 & 0 & 0 & 0 & 0 & 0 & 0 & 0 & 0 & 0 & 0 \\
\hline C4 SX & 0 & 0 & 0 & 0 & 0 & 0 & 0 & 0 & 0 & 0 & 0 & 0 & 0 & 0 & 0 \\
\hline C4 DX & 0 & 0 & 0 & 0 & 0 & 0 & 0 & 0 & 0 & 0 & 0 & 0 & 0 & 0 & 0 \\
\hline C5 & 0 & 000100 & 001000 & 001000 & 000010 & 000001 & 0 & 0 & 0 & 0 & 0 & 0 & 001000 & 001000 & 000100 \\
\hline C6 & 0 & 0 & 0 & 0 & 0 & 0 & 0 & 0 & 0 & 0 & 0 & 0 & 0 & 0 & 0 \\
\hline C7 SX & 0 & 0 & 0 & 0 & 0 & 0 & 0 & 0 & 0 & 0 & 0 & 0 & 0 & 0 & 0 \\
\hline C7 DX & 0 & 0 & 0 & 0 & 0 & 0 & 0 & 0 & 0 & 0 & 0 & 0 & 0 & 0 & 0 \\
\hline C8 & 0 & 0 & 0 & 0 & 0 & 0 & 0 & 0 & 0 & 0 & 0 & 0 & 0 & 0 & 0 \\
\hline C9 & 0 & 0 & 0 & 0 & 0 & 0 & 010000 & 0 & 0 & 0 & 0 & 0 & 0 & 0 & 0 \\
\hline C10 & 0 & 0 & 0 & 0 & 0 & 0 & 0 & 0 & 0 & 0 & 0 & 0 & 0 & 0 & 0 \\
\hline C11 & 0 & 0 & 0 & 0 & 0 & 0 & 010000 & 0 & 0 & 0 & 010000 & 0 & 0 & 0 & 0 \\
\hline C12 SX & 0 & 0 & 0 & 0 & 0 & 0 & 010000 & 010000 & 010000 & 0 & 0 & 0 & 0 & 0 & 0 \\
\hline C12 DX & 0 & 0 & 0 & 0 & 0 & 0 & 010000 & 010000 & 0 & 0 & 0 & 0 & 0 & 0 & 0 \\
\hline C13 & 0 & 0 & 0 & 0 & 0 & 0 & 010000 & 010000 & 0 & 0 & 0 & 0 & 0 & 0 & 0 \\
\hline C14 & 0 & 0 & 0 & 0 & 0 & 0 & 000011 & 110000 & 0 & 0 & 0 & 000011 & 0 & 0 & 0 \\
\hline C15 & 0 & 0 & 0 & 0 & 0 & 0 & 0 & 0 & 0 & 0 & 0 & 100000 & 0 & 0 & 0 \\
\hline C16 & 0 & 0 & 0 & 0 & 0 & 0 & 0 & 0 & 0 & 0 & 0 & 100000 & 0 & 0 & 0 \\
\hline C17 & 0 & 0 & 0 & 0 & 0 & 0 & 0 & 0 & 0 & 100000 & 0 & 100000 & 0 & 0 & 0 \\
\hline
\end{tabular}

Figure 15. CFM (components fasteners matrix). 


\begin{tabular}{|c|c|c|c|c|c|c|c|c|c|c|c|c|c|c|c|c|c|c|c|c|c|}
\hline & C1 & C2 SX & C2 DX & C3 & C4 SX & C4 DX & C5 & C6 & C7 SX & C7 DX & C8 & C9 & C10 & C11 & C12 SX & C12 DX & C13 & C14 & C15 & C16 & C17 \\
\hline F1 & 0 & 0 & 0 & 0 & 0 & 0 & 0 & 0 & 0 & 0 & 0 & 0 & 0 & 0 & 0 & 0 & 0 & 0 & 0 & 0 & 0 \\
\hline F2 & 0 & 0 & 0 & 0 & 0 & 0 & 0 & 0 & 0 & 0 & 0 & 0 & 0 & 0 & 0 & 0 & 0 & 0 & 0 & 0 & 0 \\
\hline F3 & 0 & 0 & 0 & 0 & 0 & 0 & 0 & 0 & 0 & 0 & 0 & 0 & 0 & 0 & 0 & 0 & 0 & 0 & 0 & 0 & 0 \\
\hline F4 & 0 & 0 & 0 & 0 & 0 & 0 & 0 & 0 & 0 & 0 & 0 & 0 & 0 & 0 & 0 & 0 & 0 & 0 & 0 & 0 & 0 \\
\hline F5 SX & 0 & 0 & 0 & 0 & 0 & 0 & 0 & 0 & 0 & 0 & 0 & 0 & 0 & 0 & 0 & 0 & 0 & 0 & 0 & 0 & 0 \\
\hline F5 DX & 0 & 0 & 0 & 0 & 0 & 0 & 0 & 0 & 0 & 0 & 0 & 0 & 0 & 0 & 0 & 0 & 0 & 0 & 0 & 0 & 0 \\
\hline F6 & 0 & 0 & 0 & 0 & 0 & 0 & 0 & 0 & 0 & 0 & 001100 & 0 & 001100 & 0 & 0 & 0 & 0 & 0 & 0 & 0 & 0 \\
\hline F7 & 0 & 0 & 0 & 0 & 0 & 0 & 0 & 0 & 0 & 0 & 010000 & 010000 & 010000 & 010000 & 0 & 0 & 0 & 0 & 0 & 0 & 0 \\
\hline F8 & 0 & 0 & 0 & 0 & 0 & 0 & 0 & 0 & 0 & 0 & 010000 & 010000 & 010000 & 010000 & 0 & 010000 & 0 & 0 & 0 & 0 & 0 \\
\hline F9 SX & 0 & 0 & 0 & 0 & 0 & 0 & 0 & 0 & 0 & 0 & 0 & 0 & 0 & 0 & 0 & 0 & 0 & 0 & 0 & 0 & 0 \\
\hline F9 DX & 0 & 0 & 0 & 0 & 0 & 0 & 0 & 0 & 0 & 0 & 010000 & 0 & 010000 & 0 & 0 & 0 & 0 & 0 & 0 & 0 & 0 \\
\hline F10 & 0 & 0 & 0 & 0 & 0 & 0 & 0 & 0 & 0 & 0 & 0 & 0 & 0 & 0 & 0 & 0 & 0 & 0 & 0 & 0 & 0 \\
\hline F11 & 0 & 0 & 0 & 0 & 0 & 0 & 0 & 0 & 0 & 0 & 0 & 0 & 0 & 0 & 0 & 0 & 0 & 0 & 0 & 0 & 0 \\
\hline$F 12$ & 0 & 0 & 0 & 0 & 0 & 0 & 0 & 0 & 0 & 0 & 0 & 0 & 0 & 0 & 0 & 0 & 0 & 0 & 0 & 0 & 0 \\
\hline F13 & 0 & 0 & 0 & 0 & 0 & 0 & 0 & 0 & 0 & 0 & 0 & 0 & 0 & 0 & 0 & 0 & 0 & 0 & 0 & 0 & 0 \\
\hline
\end{tabular}

Figure 16. FCM (fasteners components matrix).

\begin{tabular}{|c|c|c|c|c|c|c|c|c|c|c|c|c|c|c|c|c|c|c|c|c|c|}
\hline & C1 & C2 SX & C2 DX & C3 & C4 SX & C4 DX & C5 & C6 & C7 SX & \begin{tabular}{|c|} 
C7 DX \\
\end{tabular} & C8 & C9 & C10 & C11 & C12 SX & C12 DX & $\mathrm{C} 13$ & C14 & C15 & C16 & C17 \\
\hline C1 & 0 & 111110 & 111101 & 110111 & 110100 & 110100 & 000100 & 0 & 0 & 0 & 011111 & 0 & 010000 & 011111 & 001111 & 001111 & 001111 & 001111 & 001111 & 0 & 101111 \\
\hline C2 sx & 0 & 0 & 0 & 0 & 0 & 0 & 0 & 0 & 0 & 0 & 0 & 0 & 0 & 0 & 0 & 0 & 0 & 0 & 0 & 0 & 0 \\
\hline C2 DX & 0 & 0 & 0 & 0 & 0 & 0 & 0 & 0 & 0 & 0 & 0 & 0 & 0 & 0 & 0 & 0 & 0 & 0 & 0 & 0 & 0 \\
\hline C3 & 0 & 111110 & 111101 & 0 & 111110 & 111101 & 110111 & 0 & 111110 & 111101 & 0 & 0 & 0 & 0 & 0 & 0 & 0 & 0 & 0 & 0 & 0 \\
\hline C4 SX & 0 & 000010 & 0 & 0 & 0 & 0 & 0 & 0 & 000010 & 0 & 0 & 0 & 0 & 0 & 0 & 0 & 0 & 0 & 0 & 0 & 0 \\
\hline C4 DX & 0 & 0 & 000001 & 0 & 0 & 0 & 0 & 0 & 0 & 000001 & 0 & 0 & 0 & 0 & 0 & 0 & 0 & 0 & 0 & 0 & 0 \\
\hline C5 & 0 & 111110 & 111101 & 0 & 0 & 0 & 0 & 000100 & 0 & 0 & 0 & 0 & 0 & 0 & 0 & 0 & 0 & 0 & 0 & 0 & 0 \\
\hline C6 & 0 & 0 & 0 & 0 & 0 & 0 & 0 & 0 & 0 & 0 & 0 & 0 & 0 & 0 & 0 & 0 & 0 & 0 & 0 & 0 & 0 \\
\hline C7 Sx & 0 & 111100 & 0 & 0 & 0 & 0 & 0 & 0 & 0 & 0 & 0 & 0 & 0 & 0 & 0 & 0 & 0 & 0 & 0 & 0 & 0 \\
\hline C7 DX & 0 & 0 & 111100 & 0 & 0 & 0 & 0 & 0 & 0 & 0 & 0 & 0 & 0 & 0 & 0 & 0 & 0 & 0 & 0 & 0 & 0 \\
\hline C8 & 0 & 0 & 0 & 0 & 0 & 0 & 0 & 0 & 0 & 0 & 0 & 0 & 0 & 0 & 0 & 0 & 0 & 0 & 0 & 0 & 0 \\
\hline$c 9$ & 0 & 0 & 0 & 0 & 0 & 0 & 0 & 0 & 0 & 0 & 010000 & 0 & 010000 & 001111 & 0 & 0 & 0 & 0 & 0 & 0 & 0 \\
\hline C10 & 0 & 0 & 0 & 0 & 0 & 0 & 0 & 0 & 0 & 0 & 010000 & 0 & 0 & 0 & 0 & 0 & 0 & 0 & 0 & 0 & 0 \\
\hline C11 & 0 & 0 & 0 & 0 & 0 & 0 & 0 & 0 & 0 & 0 & 010000 & 0 & 010000 & 0 & 0 & 0 & 0 & 0 & 0 & 0 & 0 \\
\hline $\mathrm{C12} \mathrm{sX}$ & 0 & 0 & 0 & 0 & 0 & 0 & 0 & 0 & 0 & 0 & 010000 & 010000 & 010000 & 010000 & 0 & 010000 & 010000 & 0 & 0 & 0 & 0 \\
\hline C12 DX & 0 & 0 & 0 & 0 & 0 & 0 & 0 & 0 & 0 & 0 & 010000 & 010000 & 010000 & 010000 & 0 & 0 & 0 & 0 & 0 & 0 & 0 \\
\hline $\mathrm{C} 13$ & 0 & 0 & 0 & 0 & 0 & 0 & 0 & 0 & 0 & 0 & 010000 & 010000 & 010000 & 010000 & 0 & 010000 & 0 & 0 & 0 & 0 & 0 \\
\hline C14 & 0 & 0 & 0 & 110100 & 0 & 0 & 0 & 0 & 0 & 0 & 011111 & 011111 & 011111 & 011111 & 011111 & 011111 & 011111 & 0 & 101111 & 101111 & 101111 \\
\hline C15 & 0 & 0 & 0 & 0 & 0 & 0 & 0 & 0 & 0 & 0 & 0 & 0 & 0 & 0 & 0 & 0 & 0 & 0 & 0 & 100000 & 100000 \\
\hline C16 & 0 & 0 & 0 & 0 & 0 & 0 & 0 & 0 & 0 & 0 & 0 & 0 & 0 & 0 & 0 & 0 & 0 & 0 & 0 & 0 & 001111 \\
\hline C17 & 0 & 0 & 0 & 0 & 0 & 0 & 0 & 0 & 0 & 0 & 0 & 0 & 0 & 0 & 0 & 0 & 0 & 0 & 0 & 0 & 0 \\
\hline
\end{tabular}

Figure 17. CCM (components components matrix).

\begin{tabular}{|c|c|c|c|c|c|c|c|c|c|c|c|c|c|c|c|}
\hline & F1 & F2 & F3 & F4 & F5 SX & F5 DX & F6 & F7 & F8 & F9 SX & F9 DX & F10 & F11 & F12 & F13 \\
\hline F1 & 0 & 0 & 0 & 0 & 0 & 0 & 0 & 0 & 0 & 0 & 0 & 0 & 0 & 0 & 0 \\
\hline F2 & 0 & 0 & 000100 & 000100 & 0 & 0 & 0 & 0 & 0 & 0 & 0 & 0 & 0 & 0 & 0 \\
\hline F3 & 0 & 0 & 0 & 001000 & 0 & 0 & 0 & 0 & 0 & 0 & 0 & 0 & 0 & 0 & 0 \\
\hline F4 & 0 & 0 & 0 & 0 & 0 & 0 & 0 & 0 & 0 & 0 & 0 & 0 & 0 & 0 & 0 \\
\hline F5 SX & 0 & 0 & 0 & 0 & 0 & 0 & 0 & 0 & 0 & 0 & 0 & 0 & 0 & 0 & 0 \\
\hline F5 DX & 0 & 0 & 0 & 0 & 0 & 0 & 0 & 0 & 0 & 0 & 0 & 0 & 0 & 0 & 0 \\
\hline F6 & 0 & 0 & 0 & 0 & 0 & 0 & 0 & 0 & 0 & 0 & 0 & 0 & 0 & 0 & 0 \\
\hline F7 & 0 & 0 & 0 & 0 & 0 & 0 & 010000 & 0 & 0 & 0 & 0 & 0 & 0 & 0 & 0 \\
\hline F8 & 0 & 0 & 0 & 0 & 0 & 0 & 010000010000 & 0 & 0 & 0 & 0 & 0 & 0 & 0 \\
\hline F9 SX & 0 & 0 & 0 & 0 & 0 & 0 & 0 & 0 & 0 & 0 & 0 & 0 & 0 & 0 & 0 \\
\hline F9 DX & 0 & 0 & 0 & 0 & 0 & 0 & 0 & 0 & 0 & 0 & 0 & 0 & 0 & 0 & 0 \\
\hline F10 & 0 & 0 & 0 & 0 & 0 & 0 & 0 & 0 & 0 & 0 & 0 & 0 & 0 & 0 & 0 \\
\hline F11 & 0 & 0 & 0 & 0 & 0 & 0 & 0 & 0 & 0 & 0 & 0 & 0 & 0 & 0 & 0 \\
\hline F12 & 0 & 0 & 0 & 0 & 0 & 0 & 0 & 0 & 0 & 0 & 0 & 0 & 001000 & 0 & 0 \\
\hline F13 & 0 & 0 & 0 & 0 & 0 & 0 & 0 & 0 & 0 & 0 & 0 & 0 & 000100 & 000100 & 0 \\
\hline
\end{tabular}

Figure 18. FFM (fasteners fasteners matrix).

From the four submatrices, we can get the DPM (Figure 19). A random sequence is chosen to try to disassemble the fasteners. In our case, this sequence is:

F1, F2, F3, F4, F5 SX, F5 DX, F6, F7, F8, F9 SX, F9 DX, F10, F11, F12, F13 (i.e., we try to remove the fasteners in the order in which they are presented in Table 3b). Following this order, we note that F1 is the first DPM fastener with only 0 along the line, which is why it can be removed, together with the corresponding row and column. Subsequently, it is checked whether there is the possibility to remove one or more components (in this case C6) and then proceed following the rules of the algorithm previously illustrated. Towards the end of the procedure, it is interesting to note how the algorithm leads to the creation of two modules: $\mathrm{M} 1=(\mathrm{C} 1, \mathrm{C} 14)$ and $\mathrm{M} 2=(\mathrm{C} 3, \mathrm{C} 5)$. 


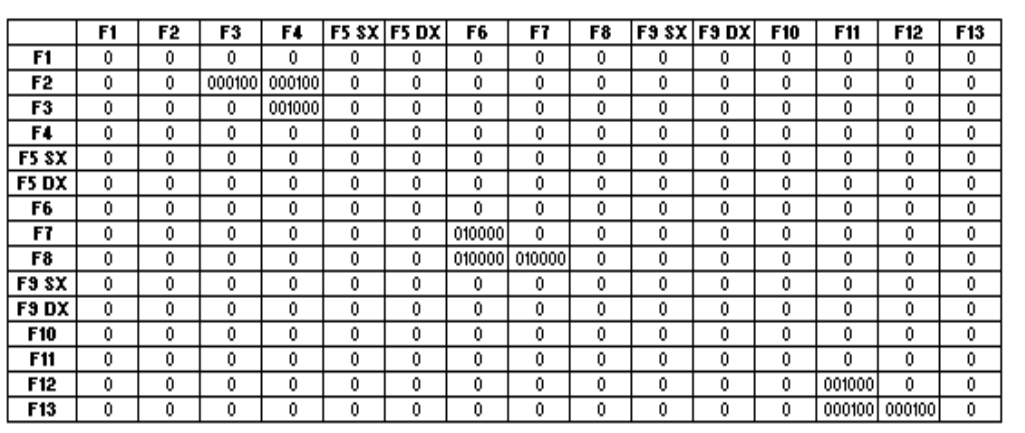

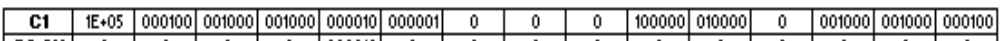

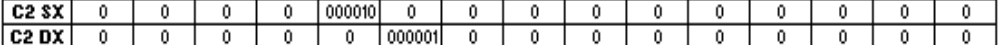

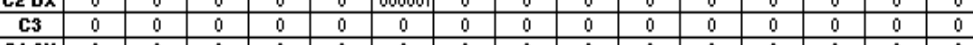

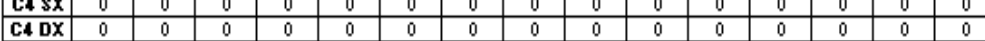



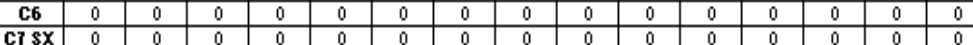

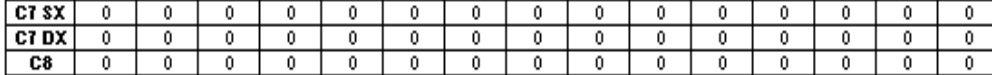

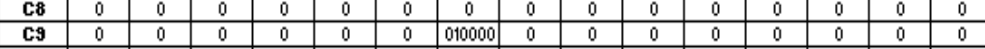

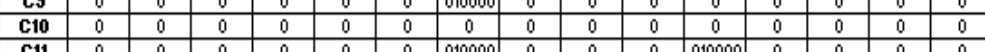

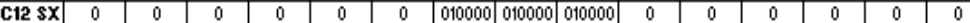



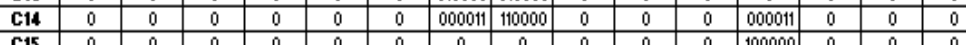

\begin{tabular}{|cccccc|c|c|c|c|c|c|c|c|c|c|c|}
$\mathbf{C} 15$ & 0 & 0 & 0 & 0 & 0 & 0 & 0 & 0 & 0 & 0 & 0 & 100000 & 0 & 0 & 0 \\
\hline $\mathbf{C} 16$ & 0 & 0 & 0 & 0 & 0 & 0 & 0 & 0 & 0 & 0 & 0 & 100000 & 0 & 0 & 0 \\
\hline
\end{tabular}

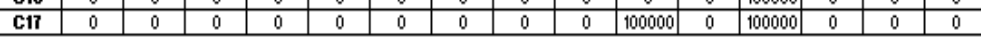

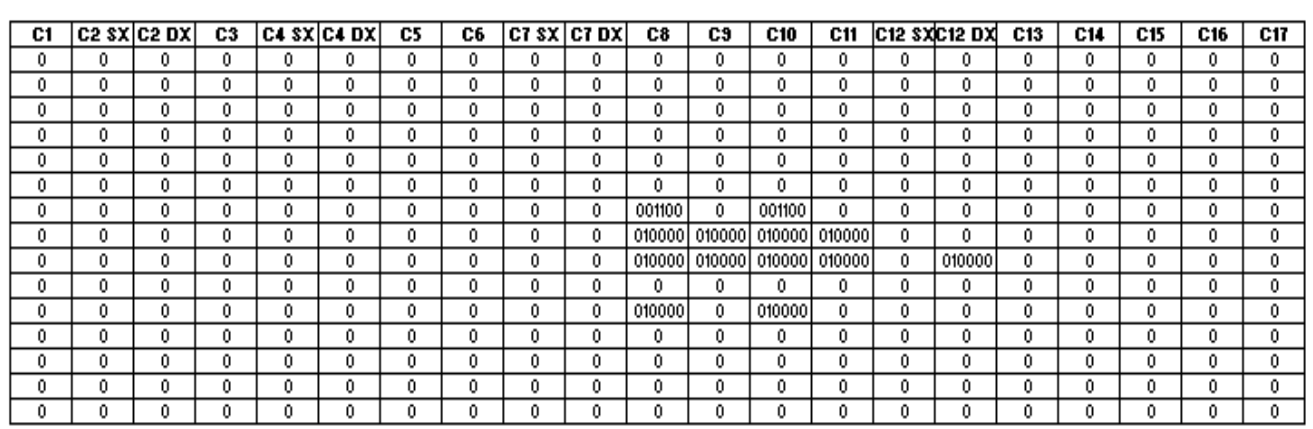

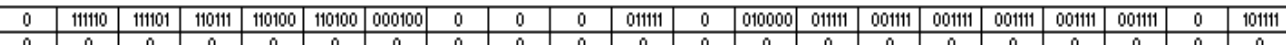

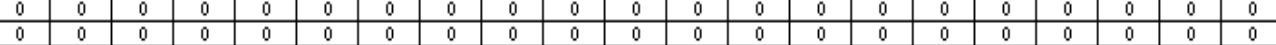

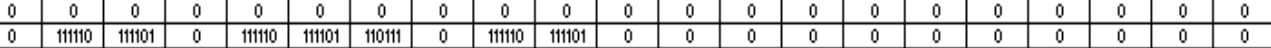

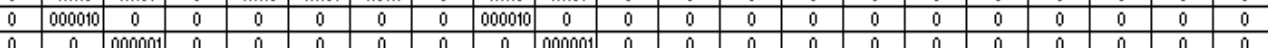

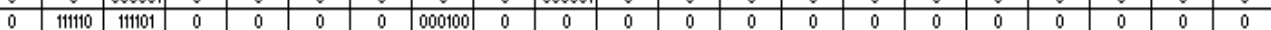
\begin{tabular}{l|lllllllllllllllllllllllllll}
0 & 0 & 0 & 0 & 0 & 0 & 0 & 0 & 0 & 0 & 0 & 0 & 0 & 0 & 0 & 0 & 0 & 0 & 0 & 0 & 0 \\
\hline
\end{tabular}

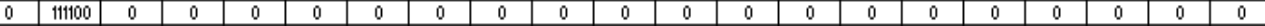
\begin{tabular}{llllllllllllllllllll|lll}
0 & 0 & $11+1+100$ & 0 & 0 & 0 & 0 & 0 & 0 & 0 & 0 & 0 & 0 & 0 & 0 & 0 & 0 & 0 & 0 & 0 & 0 \\
\hline 0 & 0 & 0 & 0 & 0 & 0 & 0 & 0 & 0 & 0 & 0 & 0 & 0 & 0 & 0 & 0 & 0 & 0 & 0 & 0 & 0 \\
\hline
\end{tabular}





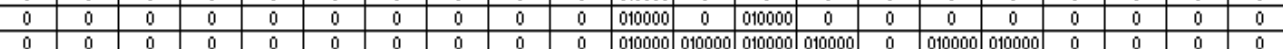

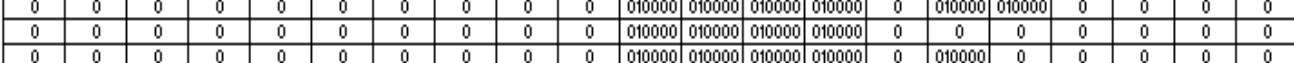





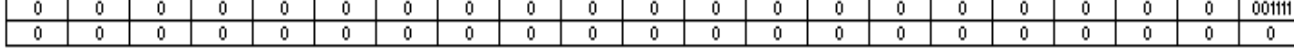

Figure 19. DPM (disassembly precedence matrix). 
Although the method provides for the parallel disassembly of M1 and M2, in our case, it is not necessary to disassemble M2, since the target component C14 belongs to M1. Furthermore, disassembling M2 in parallel would require the presence of a second operator, with a consequent increase in costs for carrying out an operation that is not necessary for our purpose.

The disassembling sequence obtained is the following (nomenclature with differentiation between components and fasteners):

16 SX INF, 16 DX INF, F1, C6, C8, C10, F4, F3, F2, F5 SX, C2 SX, C7 SX, C4 SX, F5 DX, C2 DX, C7 DX, C4 DX, F6, F9 SX, F9 DX, C11, C9, F7, C12 DX, C13, F8, C12 SX, F10, C17, C16, C15, F11, F12, F13, M2, C14.

Then, we obtain the equivalent sequence (nomenclature with numbering of the bill of materials): 16 SX INF, 16 DX INF, 7, 6, 12, 17, 11, 10, 8, 13 SX, 2 SX, 9 SX, 4 SX, 13 DX, 2 DX, 9 DX, 4 DX, 15, 26 SX, $26 \mathrm{DX}, 19,14,18,20 \mathrm{DX}, 22,21,20 \mathrm{SX}, 28,29,27,25,30,31,32, \mathrm{M} 2,24$.

Observing the sequence obtained in this case, differently from the result obtained with the first method, we note that we did not carry out a complete disassembly of the reduction unit thanks to the generation of the M2 module which was removed without being further decomposed.

\subsubsection{Sequence Created by the Authors}

The sequence hypothesized by the authors was realized on the knowledge of the gearbox that was acquired during the three-dimensional modeling phase. Authors relied mainly on intuition and common sense in addition to experience. The general considerations made for the other two methods also apply in this case.

First of all, authors proceeded to remove the two lower drain plugs to allow the oil to escape. Then, they removed all the connecting organs that hold the upper casing together with the lower one. They considered the formation of a subassembly S1 consisting of the filler cap and the upper body: $\mathrm{S} 1=(5,6)$. The loading cap was removed with the upper casing as it was not necessary to remove it individually to reach our target component (the worm shaft) and no particular complications were involved in the operations to be performed. The subassembly was then removed. The goal was to remove the screw by pulling it out of the right side of the casing, without completely disassembling the lower part. Once the tab 28 had been removed, the various elements located on the right side of the lower casing were removed, until we had reached our objective.

The sequence of disassembly obtained is as follows: 16 SX INF, 16 DX INF, 30, 31, 32, 11, 10, 8, 13 DX, 13 SX, 2 SX, 9 SX, 2 DX, 9 DX, 7, S1, 4 SX, 4 DX, 3, 28, 12, 17, 15, 26 DX, 19, 14, 18, 20 DX, 22, 21, 20 SX, 24.

During the disassembly, the authors tried to perform in succession the removal of components and/or fasteners that required the same work tool or that, depending on the case, were located on the same side of the gearbox, thus reducing the running time and fatigue to be done.

\subsubsection{Calculation of Disassembly Times and Comparison of the Results Obtained}

Now we want to evaluate the three disassembly sequences using the temporal criterion. Through the help of some tables, the time needed to complete the individual operations was estimated and the sequence that requires the least time to disassemble was sought.

For the estimate of the disassembly times, the authors referred to two essays: The first is "Disassembly Analysis through Time Estimation and Other Metrics" by Ehud Kroll and Brad S. Carver, while the second is "Evaluation of Disassemblability to Enable Design for Disassembly in Mass Production" by Anoop Desai and Anil Mital. The method adopted consists of an indirect estimate of the times. The focus is in fact placed on some parameters such as the structural aspect of the parts (e.g., symmetry, size, weight, center of gravity), the organizational aspect of the parts (e.g., product structure, standardization, variability), the pre-process (e.g., work space, information on disassembly, degree of automation) and the in-process (e.g., direction of disassembly, hand mechanisms, interference). 
After defining some influencing factors of disassembly, a quantitative assessment was provided by assigning scores in TMU (time measurement unit). For this phase, the tables in Anoop Desai and Anil Mital's essay [9] were taken as a reference.

First of all, for each element, you define which task you want to perform (unscrew, push, open, etc.) and with which tool this operation is performed (by hand, with a screwdriver, with a key, etc.). The function that the various parts play after being disassembled is then defined: In fact, at the end of their life (EOL), they can be recycled (recycling), regenerated (remanufacturing) or reused (reuse). In cases where they are recycled, only the material of the components is still used to perform other functions, and therefore, it is necessary to bear costs related to disassembling, cleaning, and recycling. If the components are regenerated instead, they are disassembled from the product structure and are subject to a technological redesign that allows increasing or simplifying the performance: In this case, the costs to be incurred are those related to disassembly, cleaning, redesign, and working to revitalize them and to assemble them again. Finally, a component subject to reuse is disassembled from the product structure and is reused as is, without undergoing technological improvements or redesign: The costs to be incurred are those related to disassembly, cleaning, and assembly.

Once the function that elements acquire after the disassembly is indicated, proceed with the assignment of the scores in TMU referring to [9]. It can be seen that in the paper, several factors that influence disassembly can be taken into consideration, such as: The disassembling force (the lower the amount of force, the lower the amount of effort to be made), the movement of the material (a smoother grip of the component implies less time taken), the use of tools (ideally, you would like to disassemble without the use of tools, but in practice we try to minimize the number of necessary tools), accessibility (easy access to components and fasteners is essential for fast and efficient disassembly), and positioning of the working tool (the lower the precision required from the instrument, the less time will be used).

Concerning the case study of the gearbox, the authors decided to allocate all components and fasteners to reuse, except for the transmission shaft with the worm screw, which was destined for recycling. To obtain the time estimate of the disassembly sequences, it was sufficient to multiply the value in TMU by $0.036(1 \mathrm{TMU}=0.036 \mathrm{~s})$. It can be seen how the sequence obtained with the first method corresponds to a value of 9415 TMU (corresponding to $338.94 \mathrm{~s}$ ) and how this value is the highest among the three sequences made: In fact, the sequence obtained with the second method had a score of $9324 \mathrm{TMU}$, which corresponds to $335.66 \mathrm{~s}$, while the sequence devised by the authors had a score of $8255 \mathrm{TMU}$, corresponding to $297.18 \mathrm{~s}$. The sequence obtained with the first method is the longest since it has led to a complete disassembly of the gearbox, unlike the other two which, by contrast, are faster because we reduced the number of elements to be disassembled. Finally, we can observe how the components and the fasteners did not have the same effect on the duration of the disassembly: The bearings, for example, were among the longest components to be removed due to their position, the use of tools, the force to be exerted, and the precision with which it was needed to operate, unlike nuts, rosettes or screws, which were disassembled in a short time because they were easily accessible and removable by applying a limited force.

\subsubsection{Economic Analysis}

To better understand the real advantages that design for disassembly offers, an economic analysis was carried out going to quantify the savings that you can have between the sequences identified in the case study. First of all, the authors had to quantify the cost that a company must support for one of its employees and, to this end, they referred to the data reported by the Italian Ministry of Labor and Social Policies (https://www.lavoro.gov.it/temi-e-priorita/rapporti-di-lavoro-e-relazioni-industriali/ focus-on/Analisi-economiche-costo-lavoro/Pagine/Settore-metalmeccanico-industria.aspx): The data in question are updated to October 2017 and refer to the workers belonging to companies in the private engineering industry and the installation of plants. Taking as a reference the values relating to a worker hired at the 4th level indefinitely, we can obtain the following data: 
Average annual cost $=€ 34,347.52$; average hourly cost $=€ 21.47$; theoretical annual hours $=40 \mathrm{~h}$ * 52.2 weeks $=2088$; hours worked average per year $=1600$.

Considering one of the disassembly sequences, knowing the duration, we were able to calculate the number of pieces processed in a year and, subsequently, we obtained the unit cost. To compare the three sequences, the authors took the least productive one (that is the one made with the first method) and calculated the annual cost. Finally, the authors calculated the cost related to the production of an equal quantity of products made with the other two sequences and compared it with the cost related to the less productive case, thus obtaining the savings that we were able to obtain.

$$
\begin{aligned}
& \text { Pieces worked per year }\left[\frac{\mathrm{pcs}}{\text { year }}\right]=\frac{\text { average hours worked per year }\left[\frac{\mathrm{h}}{\text { year }}\right]}{\text { hours employed for a piece }\left[\frac{\mathrm{h}}{\mathrm{pcs}}\right]} \\
& \text { Unit cost }[\overline{\mathrm{pcs}}]=\frac{\text { Average annual cost }\left[\frac{-}{\text { year }}\right]}{\text { Pieces worked per year }\left[\frac{\mathrm{pcs}}{\text { year }}\right]} \\
& \text { Annual cost }\left[\frac{}{\text { year }}\right]=\text { unit cost }[\overline{\mathrm{pcs}}] * \text { Pieces worked per year }\left[\frac{\mathrm{pcs}}{\text { year }}\right]
\end{aligned}
$$

It can be seen how a good design of the disassembling sequence allows having no indifferent advantages on the economic side (in our case, we can save over $€ 4000 /$ year), also considering the fact that the sequence conceived by the authors (the most advantageous) is not said to be the best ever: If we continued to search for other possible disassembling sequences, we would probably have reached a sequence that was even more advantageous than this (Table 5).

Table 5. Results and comparison among the sequences studied and applied.

\begin{tabular}{ccccccc}
\hline Sequence & Time (min) & Time (h) & $\begin{array}{c}\text { Components } \\
\text { Worked for } \\
\text { One Year } \\
\text { (pcs/Year) }\end{array}$ & $\begin{array}{c}\text { Unit Cost } \\
\text { (€/pcs) }\end{array}$ & $\begin{array}{c}\text { Cost to Produce } \\
\text { 16991 pcs/Year } \\
\text { (Case Less } \\
\text { Productive) }\end{array}$ & $\begin{array}{c}\text { Annual } \\
\text { Savings } \\
\text { (€/Year) }\end{array}$ \\
\hline $\begin{array}{c}\text { Selectable } \\
\text { disassembly strategy }\end{array}$ & 5.65 & 0.094 & 16,991 & 2.02 & $34,321.82$ & 0 \\
\hline $\begin{array}{c}\text { Partial-parallel } \\
\text { disassembly }\end{array}$ & 5.59 & 0.093 & 17,174 & 2.00 & 339.8200 & 339.82 \\
\hline Authors sequence & 4.95 & 0.083 & 19,393 & 1.77 & 30074,07 & 4247,75 \\
\hline
\end{tabular}

\subsection{Study of Augmented Reality and Possible Applications}

Augmented Reality

Augmented reality, commonly referred to as AR, consists of adding virtual elements to the real world, allowing the integration of information that is normally perceived with the five senses with information coming from a digital source. Augmented reality is therefore a type of technology that expands our physical world by adding layers of digital information on it, distinguishing itself from virtual reality, which creates a completely virtual simulated environment, depriving the user of any real reference that surrounds it.

For the operation of augmented reality, we need a device equipped with a camcorder on which an AR piece of software has been loaded, equipped with particular rendering and tracking devices. When the user points the device and looks at an object, the software recognizes it through computerized vision technology, analyzing the flow of images. Subsequently, the device hooks the desired virtual objects to the points identified in space, allowing one to follow all the movements that occur in real time. The basic principle of augmented reality, in fact, is the overlay: The camera reads the object in the 
frame and the system recognizes it and activates a new level of communication that is superimposed on reality, integrating with it and increasing the amount of detail data in relation to that object (Figure 20).

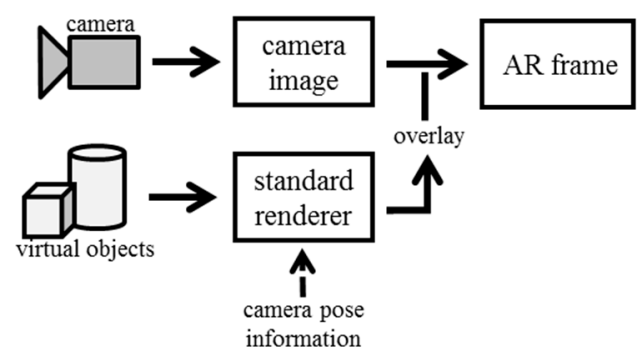

Figure 20. Augmented reality (AR) instruments' connection.

The fields of application of augmented reality are many and very diversified [14].

For example, AR can be used in the medical field to assist surgeons during interventions, viewing information on the health status of patients, or it can be used in the world of education, especially facilitating the learning of scientific subjects thanks to iteration with three-dimensional objects, and finding ample space even within museums. Augmented reality can also be used in the marketing sector to attract customers' attention, or to allow people to even view a product before buying it (for example, as Ikea or Lego do). AR is already widely used in the military field to allow soldiers to identify, in real time, possible dangers or targets. Furthermore, augmented reality is also used by firefighters to more easily understand the structure of a building and the location of fire extinguishers. Employees of airport activities, meanwhile, can view all the data relating to flights by observing only the runway and takeoff. The videogames sector is certainly the area where augmented reality is most used and has gained a lot of popularity thanks to the introduction of Nintendo's Pokémon Go into the market.

The use of augmented reality in the industrial world is very useful, as it allows viewing the product in the design phases, simplifying production and maintenance processes, improving the quality and speed of operations, integrating fully into the context of industry 4.0. The possibility of observing the product using real scales and natural interactions allows one to have a very useful vision even before realizing a physical prototype: If you want to observe the product in the environment in which it will be used, with augmented reality, this can happen fast and in a less costly manner, both in economic and temporal terms, compared to the construction of a prototype, although a digital representation is obtained and not a working prototype (Figure 21).

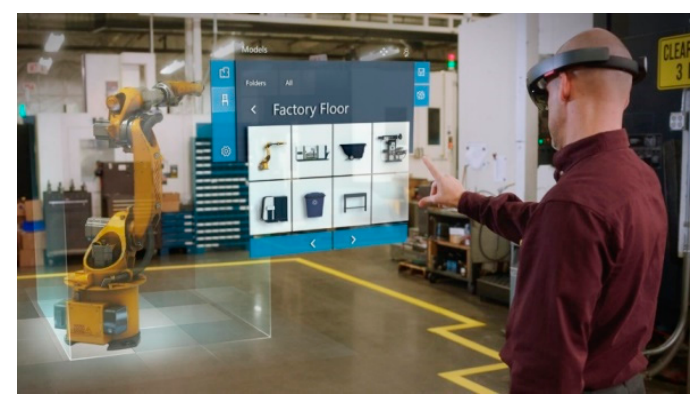

Figure 21. Design with AR.

Furthermore, it is possible to use AR to perform plant maintenance, help new staff to learn the correct procedures or assist the operator in case of non-ordinary anomalies through the help of a virtual help desk. For example, through remote assistance, you are able to control parts of a motor or an electrical system, obtaining detailed information in overlays concerning the components on which to perform checks or interventions: The information can be fixed or appear as a pop up close to the parts in question, or they can be viewed as video tutorials illustrating the correct procedures to be performed on the machine (Figure 22). 


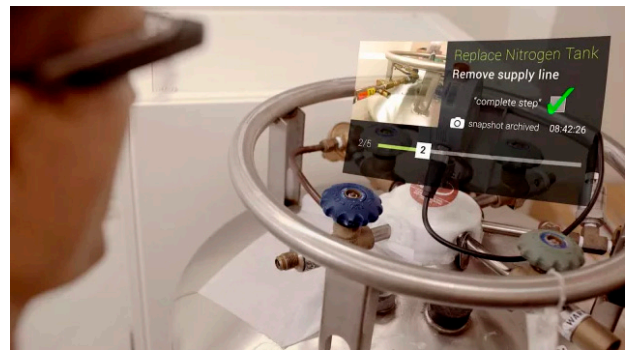

Figure 22. Maintenance with AR.

Augmented reality can also be used to conduct set-up and machine changes when it is about to start a new production, facilitating the operator in the operations to be performed and reducing machine downtime. Finally, AR finds great utility in assembly and disassembly operations, especially for more complex products. In fact, it allows one to replace the classic paper booklet of instructions, providing the operator with the information they need and indicating the procedures to be performed step by step, allowing them not to take their eyes off the piece they are working on and not to remove hands from the product or temporarily store the tools and then resume them only because they need to turn the page of the booklet, using, for example, the ability of the device to recognize voice commands.

Through an intuitive guide, which can be offered in augmented reality, it is possible to improve the quality of the service and the effective recovery of the various materials, considering that a fault-free disassembly brings great benefits both to the company and to the operators because it is an inevitable operation in the product life cycle (Figure 23).

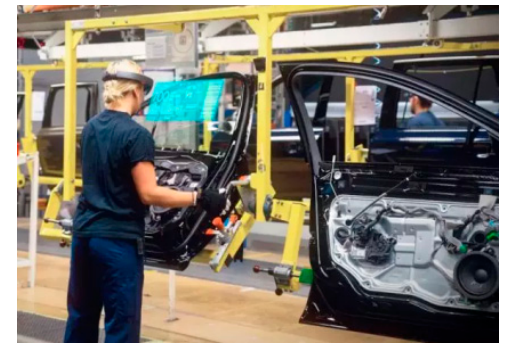

Figure 23. Assembly with AR.

The advantages obtainable from the use of augmented reality within the industrial sector are therefore of varied nature: Reduction of the risk of accidents in dangerous operations by highlighting, through specific signs, the possible risks to which the operator is exposed, reduction of the cycles of development, reduction of human error in the execution of the various operations, improvement of efficiency, and reduction of time and costs related to maintenance and production and disposal of products [15].

\section{Case Study: Application of Augmented Reality}

\section{Case Study of Speed Gearbox}

Before illustrating the possibilities of AR applied to a case study, it is important to underline some aspects about the advantages of AR application versus real application.

In fact, AR application could become more competitive than real application because it would be an opportunity "to see things before having them in our hands". With AR, we can disassemble a mechanism before producing it; we can give instructions from New York to workers working in Tokyo, from headquarters to a filial. With AR, it is possible to explain, far away, how to use and work with a machine, without being physically present in the same place as the machine. The advantages of AR disassembly application over Real disassembly applications are numerous. 
Now, in order to better understand the possibilities and possible difficulties that can be found in the use of augmented reality, the authors realized, in the AR environment, the representation of the disassembling sequence that was found to be faster among those obtained in the case study of the speed gearbox. To do this, the authors took advantage of some of the potential offered by Unity and Vuforia.

First of all, we had the need to convert the individual components assembled together from a "sldasm" format file created with Solidworks in a format that can be read by Unity, i.e., "obj". The conversion of the components must be done by exporting them from the assembly, since in this way, they are converted keeping as a reference the reference center used during the assembly, which differs from the reference center used each time to draw the individual components. Unfortunately, with Solidworks 2016, it was not possible to directly convert the components to the desired format, which is why the authors first worked with Solidworks to convert the assembly file from the sldasm format to the "step" format and then, using the three-dimensional modeling program PTC Creo Parametric 3.0, we performed the conversion of the single components present in the assembly, thus obtaining the desired files in obj (Figure 24).

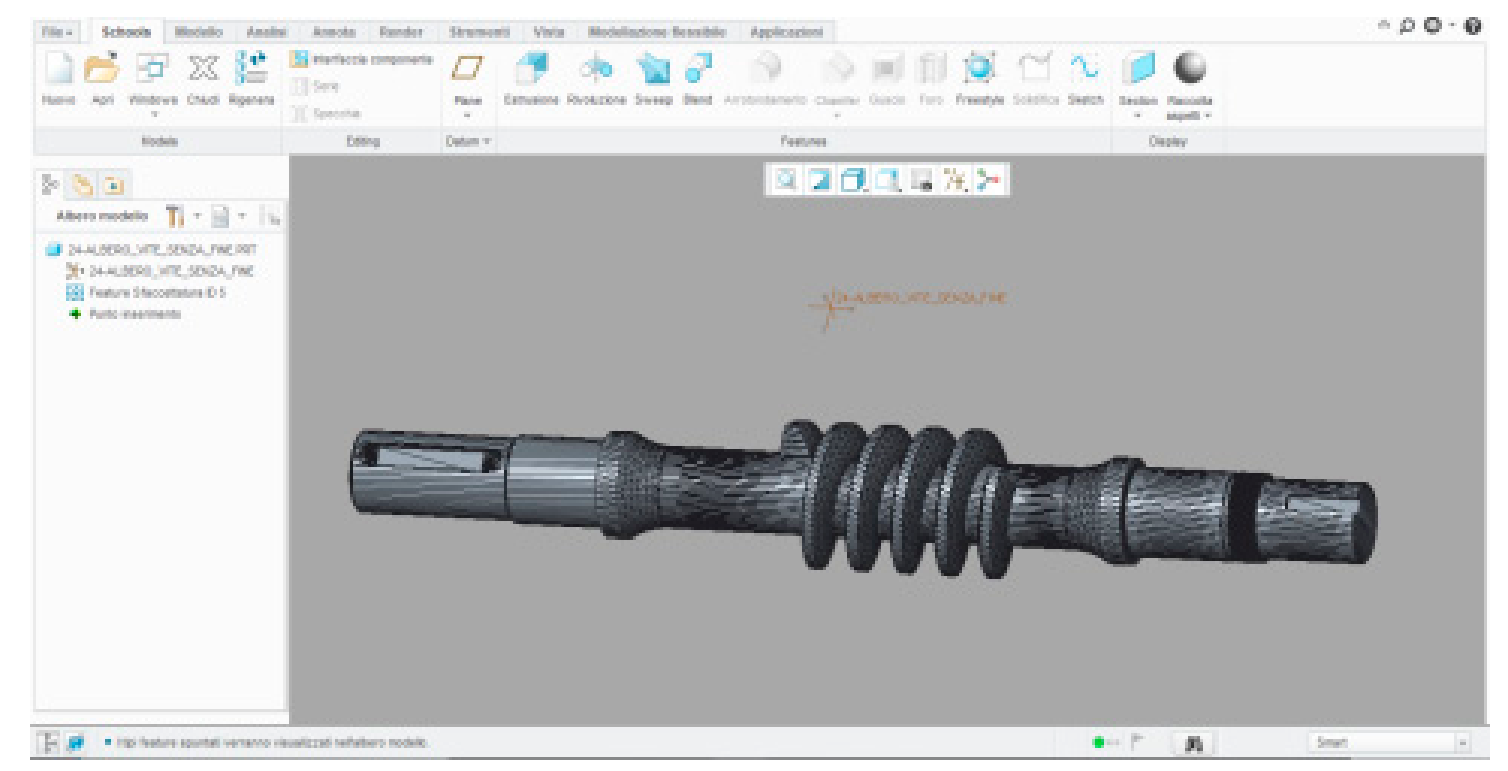

Figure 24. View of the tree in obj with PTC Creo Parametric 3.0.

Once all the parts had been converted, a new Unity project was created and all the necessary elements to use augmented reality were imported: Firstly, the authors uploaded the AR Camera and the ImageTarget from Vuforia in the GameObject menu (Figures 25 and 26).



Figure 25. Image target (used dimensions: $512 \times 885$ ). 




Figure 26. Image target with recognition points highlighted.

Then, the program to use the AR was enabled, first by activating Vuforia Augmented Reality in XR Setting and, subsequently, inserting the Vuforia license (obtainable for free from its website) among the configuration settings of Vuforia inside the AR camera previously imported.

Then, the authors proceeded to load in the Project window the folder containing all the obj files of the individual parts making up the gearbox. Then, an empty GameObject inside the Hierarchy window was created and then added the previously loaded obj files as children. Finally, after putting the GameObject on the desired scale (by default, the program adopts the meter as a unit of measure, while the dimensions of the drawings were designed in millimeters), authors proceeded to make it the child of the ImageTarget.

In this way, using a webcam to frame a print of the image used as ImageTarget with marker function, an augmented reality view of the loaded objects can be appreciated in the computer monitor once the Game mode has been started with the Play button (Figures 27-30).

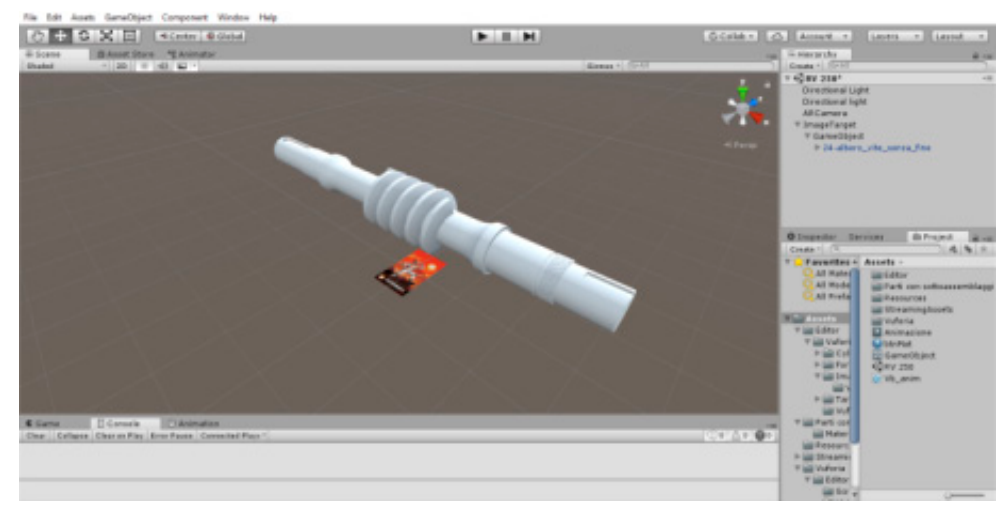

Figure 27. View of tree with Unity (scale 1:1).

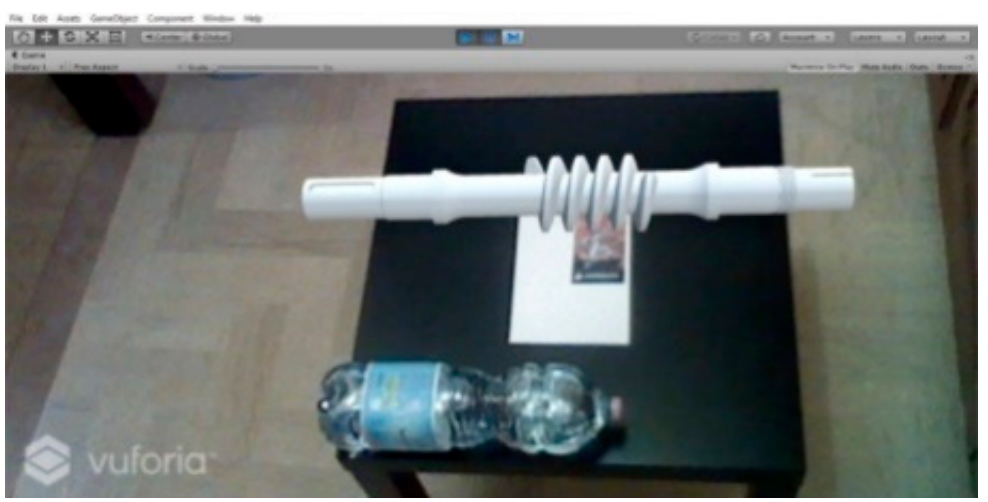

Figure 28. View of the AR tree (scale 1:1). 


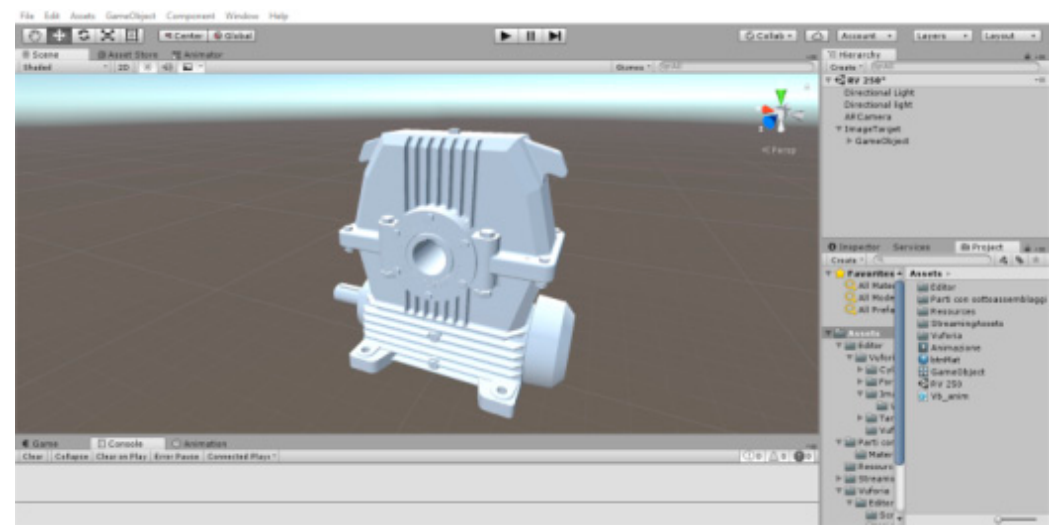

Figure 29. View of the gearbox with Unity (scale 1:1).

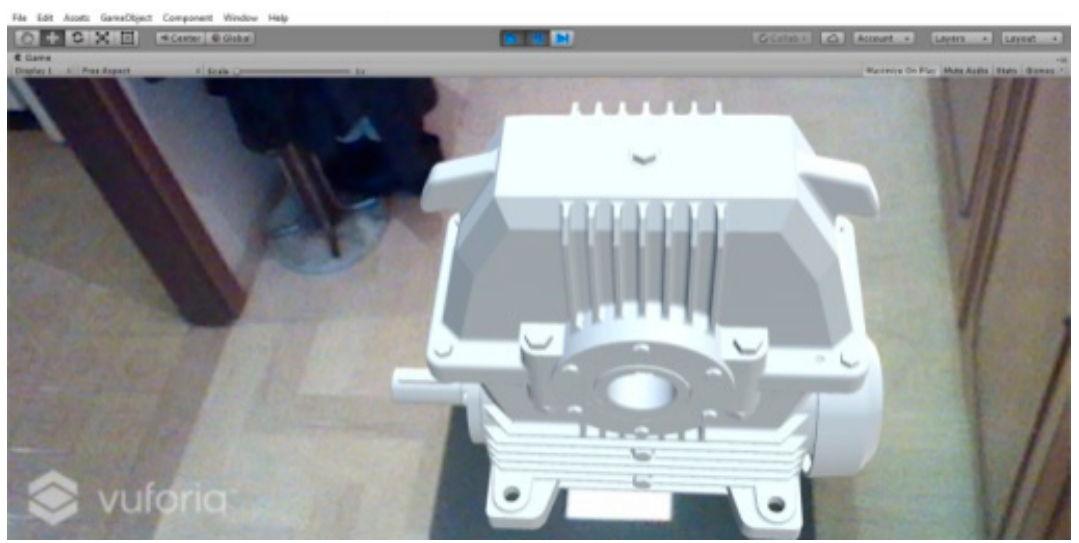

Figure 30. View of the gearbox in AR (scale 1:1).

All the work performed up to now has allowed us to obtain an AR representation of the gearbox, but in this representation, the gearbox is stationary, and the only thing that can be done is to rotate around it with the webcam.

In order to obtain greater advantages from augmented reality, the authors created an animation of the GameObject (that is, the speed gearbox) that represents the fastest disassembling sequence, thus creating an animation that helps to understand the sequence of disassembly in a better and more rapid manner. To create the animation, you create a sequence of movements that are recorded and scanned by a timeline. Once the element to be moved has been selected, a keyframe is inserted to indicate the position that the piece occupies at a given moment. Using the calculated times to move each component as a reference, it is possible to create the animation by creating, for each piece, a keyframe at the moment when the component starts to move and using the position occupied by the piece before being disassembled. Next, you enter another keyframe when the component stops moving and using the occupied position after being removed. The software is able to automatically derive intermediate frames between one keyframe and another. To make it easier to see, authors made the components turn red while they were being moved, and then they disappeared from the animation when they were removed (Figure 31).

Once the marker with the webcam is framed, the gearbox appears, and the animation is automatically started. 


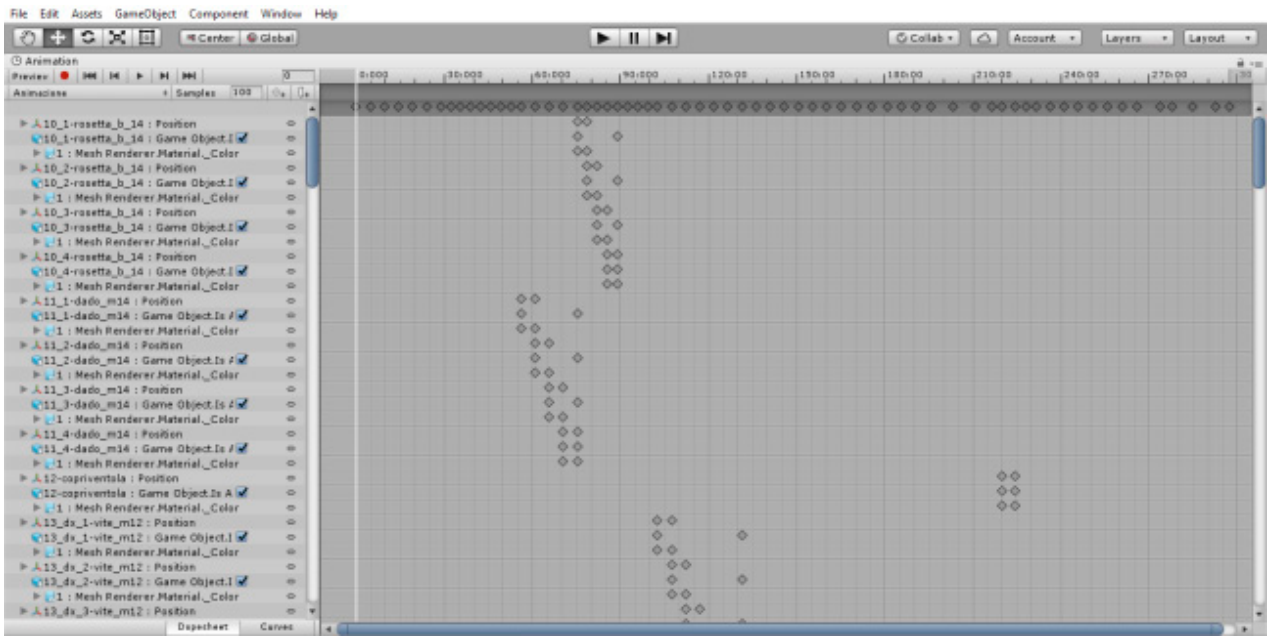

Figure 31. Gearbox animation with Unity (scale 1:1).

To have a greater interaction with the reducer represented in AR, the authors created VirtualButton, which allows the animation to start only after the virtual button is "pressed". In this way, when the webcam frames the marker, it will be possible to see the stopped gear and the virtual button positioned above the marker: As soon as the user interposes between VirtualButton and ImageTarget (for example, using the hand), the animation is started. This grants greater flexibility to the user, allowing them to view the animation when he prefers (Figure 32a,b and Figure 33a,b).



(a)



(b)

Figure 32. (a) Animation of the gearbox in AR (scale 1:4). (b) Animation of the gearbox in AR (scale 1:4).

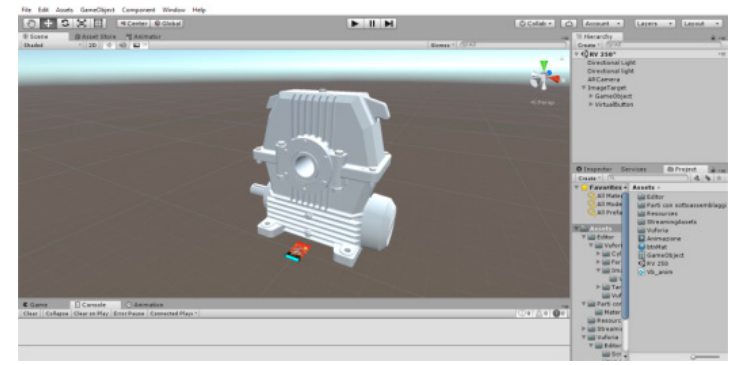

(a)

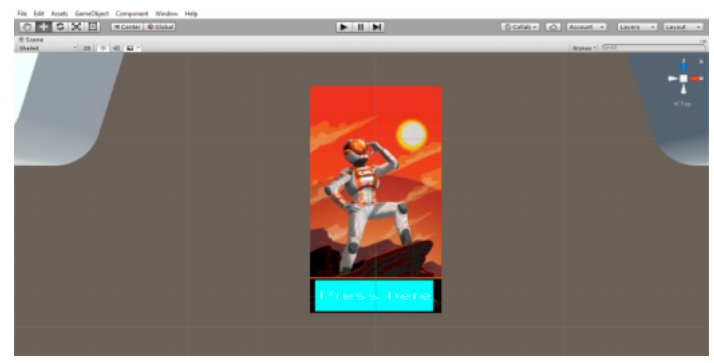

(b)

Figure 33. (a,b) View of VirtualButton with Unity (scale 1:1).

For the operation of VirtualButton (Figure 34a,b and Figure 35), it was necessary to create a script to describe the desired behavior. The script was composed using C\# programming language, developed with Visual Studio 2017. 


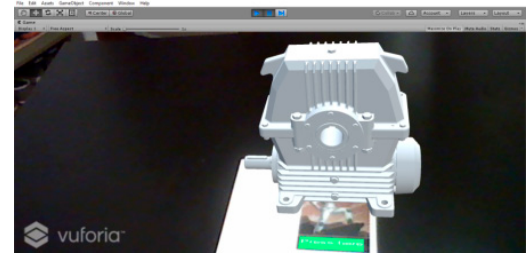

(a)

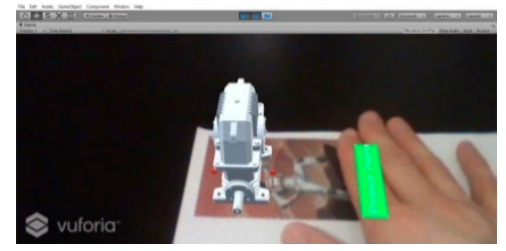

(b)

Figure 34. (a) Virtual Button in AR (1:4 scale reducer); (b) VirtualButton in AR (1:10 scale reducer).

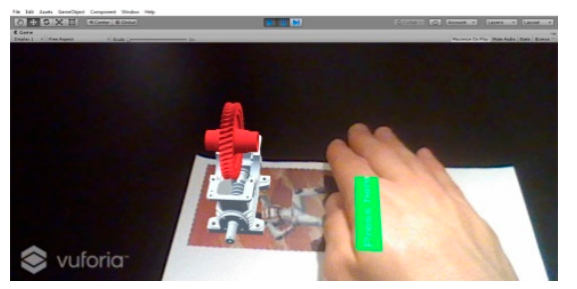

Figure 35. Animated disassembling gearbox.

\section{Discussion and Conclusions}

During the development of the present work, the authors had the opportunity to deepen and touch on how the design for disassembly is able to offer advantages from different points of view, allowing a better management of resources, in particular, the times and costs related to disassembly.

As for augmented reality and its applications, the authors learned how this technology offers considerable advantages in many areas, although it is not yet fully widespread and exploited, which is why in the years to come, we expect continuous improvements in the potential associated with it.

Applying it to the case study, the authors were able to gain a better understanding of the real dimensions of the gear in question, as well as the structure of the object as a whole and in each of its parts. The possibility to realize an animation and to manage it through the interaction with a virtual button offers concrete advantages in the speed and quality of learning, supporting the operator in the process of disassembling.

On the other hand, authors also encountered some disadvantages, noting, for example, that the time required to create the animation increases quickly if you need to consider many components or if you want to add some features to the pieces in addition to the simple movement (for example, making them disappear after being removed or changing color while moving). The greatest difficulty the authors encountered is the one related to programming, because if you want to develop further, more elaborate but also more advantageous functions (such as the possibility to pause the animation), a certain dexterity in programming is required, surely facilitated if you have some experience in this regard, which for them was quite limited.

Beyond the difficulties encountered, the possibilities that augmented reality offers are many and, if well managed, it is possible to obtain multiple advantages.

Author Contributions: Conceptualization, L.F.; Methodology, A.L.; Data Curation, G.C. and L.C.; Formal Analysis, G.D.; Validation, L.F.; Writing - original draft, L.C. and L.F.

Funding: This research received no external funding.

Acknowledgments: Authors acknowledge the important contribution of the student Luca Chinaglia.

Conflicts of Interest: The authors declare no conflict of interest. 


\section{References}

1. McMahon, C.; Browne, J. CADCAM-Principles, Practice and Manufacturing Management, 2nd ed.; Addison-Wesley: Boston, FL, USA, 1998.

2. Kalpakjian, S.; Schmid, S.R. Manufacturing Engineering and Technology, 6th ed.; Prentice Hall: Upper Saddle River, NJ, USA, 2010.

3. Ian Gibson, I.; Rosen, D.W.; Stucker, B. Additive Manufacturing Technologies: Rapid Prototyping to Direct Digital Manufacturing; Johnson Matthey Technology Review; Springer: New York, NY, USA, 2010; pp. 193-198.

4. Schilling, Strategic Management of Technological Innovation; McGraw-Hill Education: New York, NY, USA, 2013.

5. Alessandro Grandi, Gestione dei progetti d'innovazione; McGraw-Hill Education: Bologna, Italy, 2017.

6. Filippini, R.; Ulrich, K.T.; Eppinger, S.D. Design and Product Development; McGraw-Hill Education: New York, NY, USA, 2007.

7. Caligiana, G.; Liverani, A.; Francia, D.; Frizziero, L.; Donnici, G. Integrating QFD and TRIZ for innovative design. J. Adv. Mech. Des. Syst. Manuf. 2017, 11. [CrossRef]

8. Kroll, E.; Carver, B.S. Disassembly analysis through time estimation and other metrics. Robot. Comput. Integr. Manuf. 1999, 15, 191-200. [CrossRef]

9. Desai, A.; Mital, A. Evaluation of disassemblability to enable design for disassembly in mass production. Int. J. Ind. Ergon. 2003, 32, 265-281. [CrossRef]

10. Tao, F.; Bi, L.; Zuo, Y.; Nee, A.Y.C. Partial/Parallel Disassembly Sequence Planning for Complex Products. J. Manuf. Sci. Eng. 2018, 140, 011016. [CrossRef]

11. Yi, J.; Yu, B.; Du, L.; Li, C.; Hu, D. Research on the selectable disassembly strategy of mechanical parts based on the generalized CAD model. Int. J. Adv. Manuf. Technol. 2008, 37, 599-604. [CrossRef]

12. Fargione, G.; Giudice, F. Pianificazione del disassemblaggio di sistemi meccanici: Approccio mediante algoritmi genetici. In Proceedings of the XIV ADM-XXXIII AIAS: Innovazione nella Progettazione Industriale, At Bari, Italy, 31 August-2 September 2004.

13. Fargione, G.; Giudice, F.; Risitano, A. Progettazione per il disassemblaggio: applicazione di reti neurali per l'analisi della profondità di smontaggio. In Proceedings of the XIII ADM-XV INGEGRAF International Conference on Tools and Methods Evolution in Engineering Design, Naples, Italy, 4-6 June 2003.

14. Chang, M.M.L.; Ong, S.K.; Nee, A.Y.C. AR-guided Product Disassembly for Maintenance and Remanufacturing. Procedia Cirp 2017, 61, 299-304. [CrossRef]

15. de Amicis, R.; Ceruti, A.; Francia, D.; Frizziero, L.; Simoes, B. Augmented Reality for virtual user manual. Int. J. Interact. Des. Manuf. 2018, 12, 689-697. [CrossRef] 